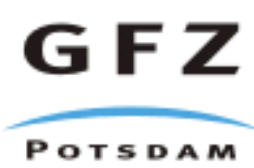

Originally published as:

Weber, M. (1994): Traveltime and amplitude anomalies at the seismic broad-band array GRF.

- Geophysical Journal International, 118, 1, 57-74.

DOI: 10.1111/j.1365-246X.1994.tb04675.x. 


\title{
Traveltime and amplitude anomalies at the seismic broad-band array GRF
}

\author{
M. Weber* \\ GeoForschungsZentrum Potsdam, Telegrafenberg A6, D-14473 Potsdam, Germany
}

Accepted 1993 December 29. Received 1993 December 27; in original form 1993 September 28

\begin{abstract}
SUMMA RY
Traveltime and amplitude residuals of $P$ waves from teleseismic events show a positive correlation at the stations of the German seismic broad-band array GRF. Fast arrivals consistently have reduced amplitudes in the four frequency ranges considered (short-period bandpass, WWSSN-SP filter, broad-band velocity and WWSSN-LP filter).

With the exception of the WWSSN-LP filter, 40-60 per cent of the average of the relative traveltime and almost 100 per cent of the average of the amplitude residuals at individual stations, with respect to the reference station $\mathrm{A} 1$, can be explained by near-surface sediment layers. These shallow structures are known from local and regional geology and are documented in borehole, local refraction and polarization studies. This aximuthal- and distance-independent term (station average) reaches values of up to $-0.55 \mathrm{~s}$ and -0.15 units in log amplitude (magnitude).

Even after the removal of these station averages, which also contain a trend of increasing crustal and uppermost mantle velocity from north to south, large azimuthal- and distance-dependent relative traveltime and magnitude residuals can be observed across the array. These residuals vary between -0.8 and $+1.1 \mathrm{~s}$ and -0.54 and +0.72 magnitude units. Negative (fast) traveltime residuals are again related to negative magnitude residuals (small amplitudes). The azimuthal- and distance-dependent patterns of these residuals are identical within three distinct clusters of stations. The main features of the residual patterns correlate well with the main fault systems and inhomogeneities near the array, some of which have been postulated previously. The velocity anomalies causing the azimuthal- and distancedependent residuals are located in crust and uppermost mantle under the array and its vicinity.

The fact that local effects like sedimentary covers are responsible for 40 per cent or more of the station average residuals demonstrates again that site effects should be removed before tomographic methods are employed. The simple stations corrections usually applied in global tomography might severely underestimate the influence of local and regional velocity anomalies, since even after the removal of the station average residual large azimuthal- and distance-dependent traveltime and amplitude anomalies remain between stations less than $100 \mathrm{~km}$ apart. These anomalies due to shallow inhomogeneities might then erroneously be mapped into features at greater depth.
\end{abstract}

Key words: amplitude residuals, $P$ waves, sediments, seismic array, site effect, tomography.

\section{INTRODUCTION}

The ampiitudes of short-period teleseismic $P$ waves often show a variation of a factor 10 or more across seismic arrays * Present address: Seismologisches Zentralobservatorium SZGRF, Krankenhausstrasse 1-3, D-91054 Erlangen, Germany. and networks (for examples, see Haddon \& Husebye 1978, Fig. 1; Nakanishi \& Motoya 1990, Table 2; Mori \& Frankel 1992, Fig. 6; Odegaard \& Doornbos 1993, Fig. 4). Source properties, such as radiation pattern, and propagation effects like geometrical spreading along the path from source to the upper mantle under the receiver, cannot 
produce such large effects across the closely spaced seismometers of an array/network. Upper mantle anomalies under the receivers together with crustal inhomogeneities and site effects due to local geology are often the cause of the large amplitude variations. Traveltime residuals produced by such anomalies have been used to investigate the crust and upper mantle (Aki, Christoffersson \& Husebye 1977; Faber, Plomerová \& Babuška 1986; Nixdorf 1986; Jeménez 1993). A joint investigation of traveltimes and amplitudes was employed by Aki (1973), Berteussen et al. (1975), Haddon \& Husebye (1978), Chang \& von Seggern (1980), Thomson \& Gubbins (1982), Butler (1983), Thomson (1983), Flatté \& Wu (1988), Nakanishi \& Motoya (1990), Mori \& Frankel (1992) and Odegaard \& Doornbos (1993) to determine the local structure under arrays/networks.

The aim of this study is to analyse the traveltime and amplitude anomalies observed at the stations of the German seismic broad-band array GRF and to gain information on the structure under the array. The GRF array is situated in south-east Germany and consists of 13 stations (Fig. 1) equipped with broad-band Wieland-Streckeisen seismometers STS1; three of the stations are three-component stations. The array has been in operation since 1976 and the maximum aperture of the array is $100 \mathrm{~km}$, for details see, e.g. Harjes \& Hanka (1986). The Jurassic limestone formation on which the array is located forms the eastern part of the South German block and is separated from the Bohemian Massif in the north-east by zones of fracturing which strike roughly NW-SE (Fig. 1).

In a previous study Faber et al. (1986) used the mislocation vector pattern of the GRF array, together with a tomographic inversion of $P$-wave traveltime residuals, to study the crust and uppermost mantle beneath the array. Their results show an increase in velocity from north to south in crust and uppermost mantle up to a depth of $120 \mathrm{~km}$ (Faber et al. 1986, Figs 9 and 10). The existence of a low-velocity zone located deeper in the upper mantle to the north-east of the array was also proposed. This anomaly is possibly connected to the boundary between the Moldanubian zone in the south and the Saxothuringian zone in the north of the array (Geologische Karte von Bayem $1: 500,000,1981)$. The low-velocity body and the velocity increase in the crust was also discussed by Nixdorf (1986). An additional high-velocity structure was derived by Faber et al. (1986) in the lithosphere towards the east-south-east of the array. The average traveltime anomalies observed at the GRF array in an enlarged data set were recently reinterpreted by Krüger \& Weber (1992) as being produced to a large extent ( $40-60$ per cent) by a wedge of low-velocity near-surface sediments with increasing thickness towards the north-north-east under the array. That site effects, like sedimentary layers of varying thickness at different stations of the GRF array, severely influence the wavefield was furthermore shown by Krüger (1994). In that study a polarization analysis was applied to $P$ waves from 11 nuclear explosions recorded at the three three-component instruments of the GRF array. The study presented here uses the traveltime and amplitude residuals of $P$ waves of up to 158 teleseismic events, which are well distributed in azimuth and distance, recorded at the 13 stations of the array.

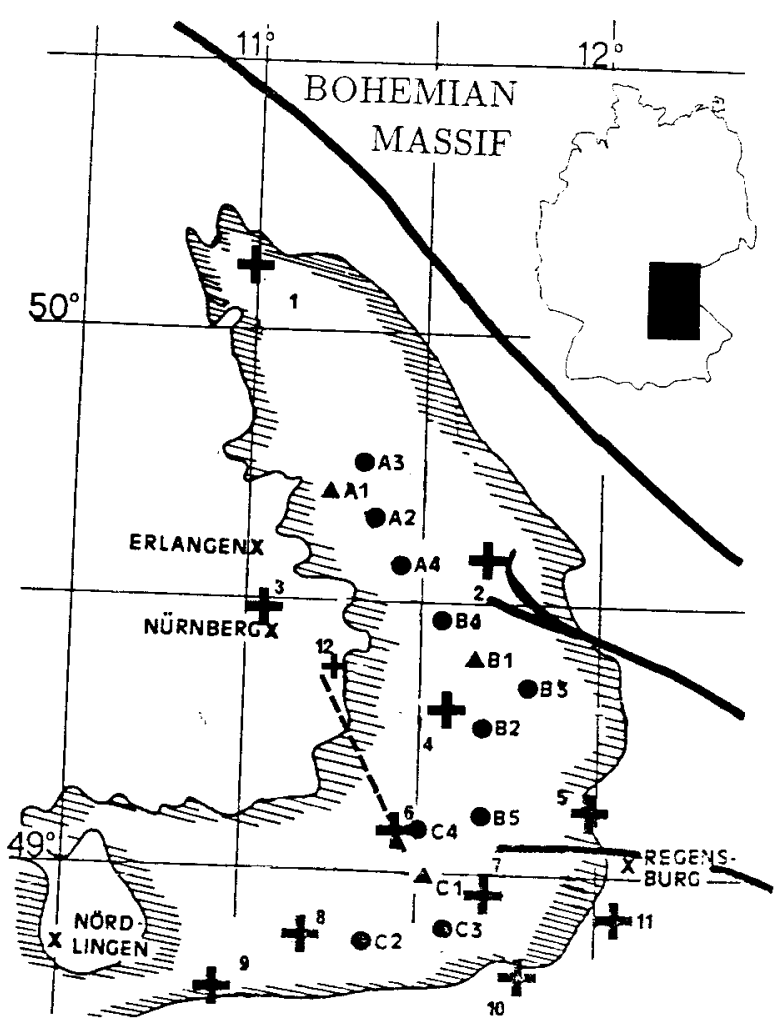

$30 \mathrm{~km}$

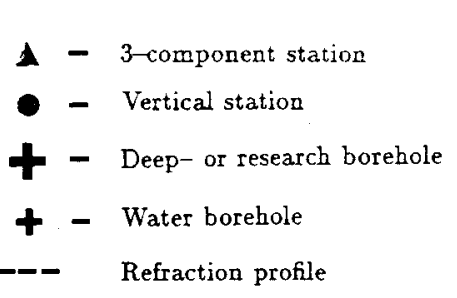

1: Staffeistein 2: Eschenfelden 4: Eschertshofen 5: Kallmünz 3: Berching 7: Riedenbur 8: Eichstăt I 9: Daiting I 10: Bad Gögging 11: Bad Abbach 12: Burgthann

Figure 1. Location of the GRF stations (vertical and threecomponent) and of boreholes (numbers 1-12) on the Franconian Jura in south-eastern Germany (see insert). Also shown is the refraction profile of Bader (1982b). Solid lines indicate the main fault systems. (Krüger \& Weber 1992, Fig. 1.)

\section{OBSERVATIONS}

\subsection{Events and frequency bands}

$P$ waves from up to 158 teleseismic events (Fig. 2) recorded between 1979 and 1991 ( $m_{b}$ between 5.0 and 6.9 and distances between 29 and 98 degrees from the GRF array) are analysed. Shorter distances are omitted to reduce the influence of the upper mantle discontinuities at the turning point between the source and the array. The events are chosen from the 341 events presently used for the mislocation vectors of the GRF array. To avoid a bias towards back azimuths of regions with high seismicity this subset of 158 events is used, which is well distributed in back azimuth and distance. Since the GRF array is a broad-band 

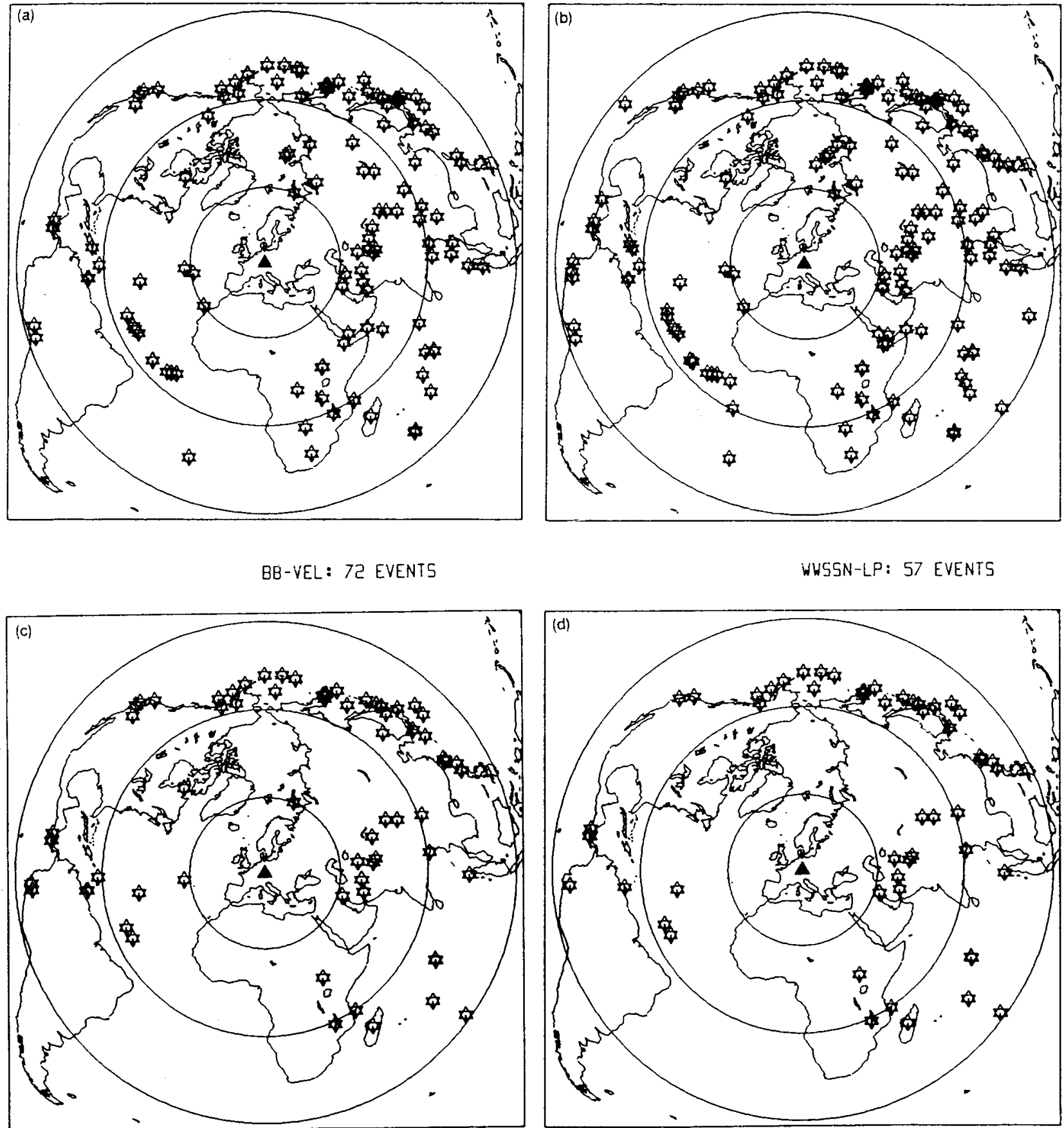

Figure 2. Distribution of epicentres (stars). The number of events is given at the top. The projection is azimuthal equidistant with GRF as the projection pole (triangle). The circles correspond to distances of 30,65 and 100 degrees from GRF. (a) Event distribution for the bandpass filter (1-4 Hz). (b) As for (a) but for the WWSSN-SP filter. (c) As for (a) but for broad-band velocity. (d) As for (a) but for the WWSSN-LP filter.

array it is possible to study the behaviour of the traveltimes and amplitudes in several frequency bands. The frequency bands (filters) used are (1) a bandpass between 1 and $4 \mathrm{~Hz}$ (BP), (2) the WWSSN-SP filter, (3) broad-band velocity (BB-VEL), and (4) the WWSSN-LP filter (Fig. 3). Typical frequencies observed are $1.1,0.8,0.4$ and $0.14 \mathrm{~Hz}$, respectively, corresponding to wavelengths of about $6,8,16$ and $46 \mathrm{~km}$ in the crust. Owing to the different signal-to-noise levels the number of events that can be used is different for the four frequency bands (see Fig. 2). 


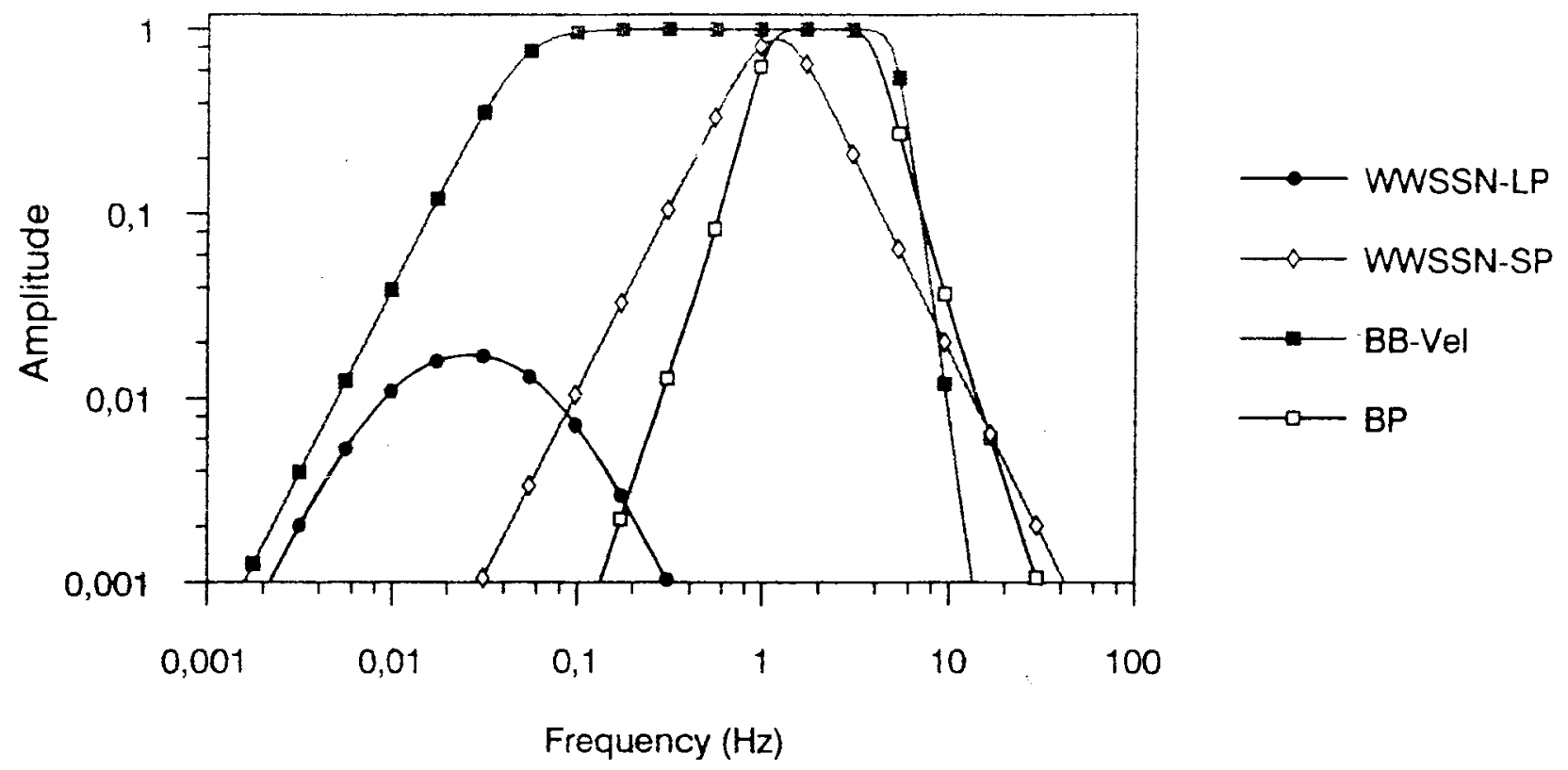

Figure 3. Frequency response functions of the four frequency bands analysed.

Nevertheless, even for the WWSSN-LP filter a fairly good coverage in back azimuth and distance is achieved.

\subsection{Trayeltime and amplitude measurement}

The traveltime measured is that of the first coherent extremum of the $P$ wave across the array, i.e. the waveform clelay time is determined. This avoids problems in the determination of the onset of a seismic phase. The determination of the time and amplitude of the extremum is done automatically within a given time window (Stammier 1993; Fig. 4) and each pick is also controlled visually. Fig. 4 shows the seismograms of two events. If there were no traveltime and amplitude anomalies the extrema would align on the time for the reference station A1 (alignment according to theoretical slowness and back azimuth) and the amplitudes at all stations would be identical. Both events have eastern back azimuths (see insert in Fig. 4), but whereas the $P$ wave in subarray $C$ in Fig. 4(a) is fast and small it is slow and large in Fig. 4(b). The measurement accuracy is usually $0.05 \mathrm{~s}$, i.e. the sampling rate of the data. The relative traveltime residual $\Delta T_{X}^{i}$ for event $i$ at station $X$ with respect to the reference station $A 1$ is defined as

$$
\begin{aligned}
\Delta T_{X}^{i} & =\left(t_{X}^{i}-t_{\mathrm{A} 1}^{i}\right)^{\text {obs }}-\left(t_{X}^{i}-t_{\mathrm{A} 1}^{i}\right)^{\text {theo }} \\
& =\left(t^{\text {obs }}-t^{\text {theo }}\right)_{X}^{i}-\left(t^{\text {obs }}-t^{\text {theo }}\right)_{\mathrm{A} 1}^{i},
\end{aligned}
$$

where $t_{X}^{i}$ is the traveltime for event $i$ at station $X$ and obs (theo) indicates the observed (theoretical) traveltime. The theoretical traveltime is calculated using source parameters taken from PDE and the IASP91 P-velocity model (Kennett \& Engdahl 1991). The advantage of relative traveltime residuals is, that errors in source parameters and the velocity deviations from the IASP91 model for the path from the source to the upper mantle beneath the array are minimized. The reasons for selecting $\mathrm{A} 1$ as the reference station are, that it is the longest running station that has been used previously as a reference station (e.g. Faber et al. 1986). Furthermore, only for station A1 have station corrections been published (Dziewonski \& Anderson 1983) and detailed geological information is available at this site since the borehole of the SRO station GRFO is less than $20 \mathrm{~m}$ away from the STS1 broad-band instrument at A1. $\Delta T_{X}^{i}$ in Fig. 4(a) (Fig. 4b) reaches values of -0.60 to $+0.05 \mathrm{~s}(-0.15$ to $+0.60 \mathrm{~s})$. Since the maximum difference in elevation within the array with respect to station $A 1$ is $0.061 \mathrm{~km}$, the elevation correction is smaller than $0.01 \mathrm{~s}$ and therefore neglected. The ellipticity correction with respect to $\mathrm{A} 1$ for the events considered is smaller than $0.03 \mathrm{~s}$, i.e. smaller than the sampling rate of $0.05 \mathrm{~s}$, and is also neglected. The relative $\log$ amplitude $\Delta M_{X}^{i}$ for event $i$ at station $X$, in the following called relative magnitude, is defined as

$\Delta M_{X}^{i}=\log _{10}\left(A_{X}^{i} / A_{\mathrm{A} 1}^{i}\right)^{\mathrm{obs}}$,

where $A_{X}^{i}$ is the observed baseline-peak amplitude for event $i$ at station $X$. The values of $\Delta M_{X}^{i}$ in Fig. 4(a) (Fig. 4b) are between -0.12 and +0.16 magnitude units $(-0.14$ and +0.37 magnitude units). Owing to the small aperture of the array in comparison with the source-receiver distances no source correction for radiation is necessary. Since the distance-dependent amplitude variations across GRF are smaller than 4 per cent this effect is neglected too.

\subsection{Relative amplitude versus traveltime residuals}

The relative $\Delta M_{X}^{i}, \Delta T_{X}^{i}$ values of all events $i$ at all stations $X$, with respect to the reference station $A 1$, are given in Fig. 5. Large variations, especially for the SP filters BP and WWSSN-SP, of more than $1 \mathrm{~s}$ and 0.6 magnitude units can be observed. The pattern of variation suggests that fast arrivals tend to have small amplitudes in all frequency bands. It can also be seen that for lower frequencies 


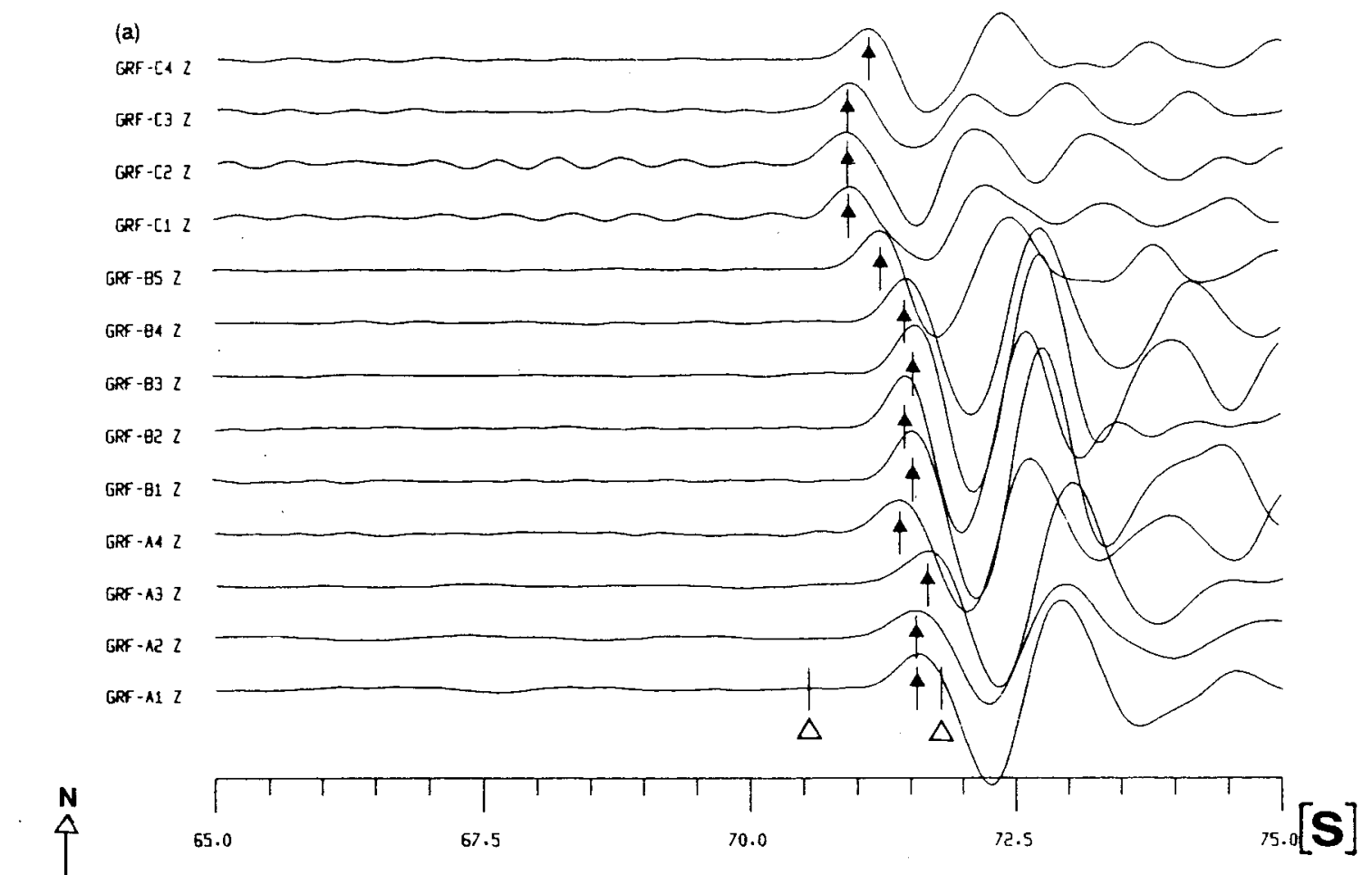

GRF $-890612+0004$

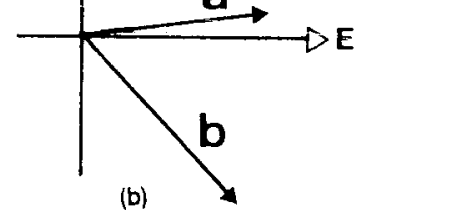

(b)

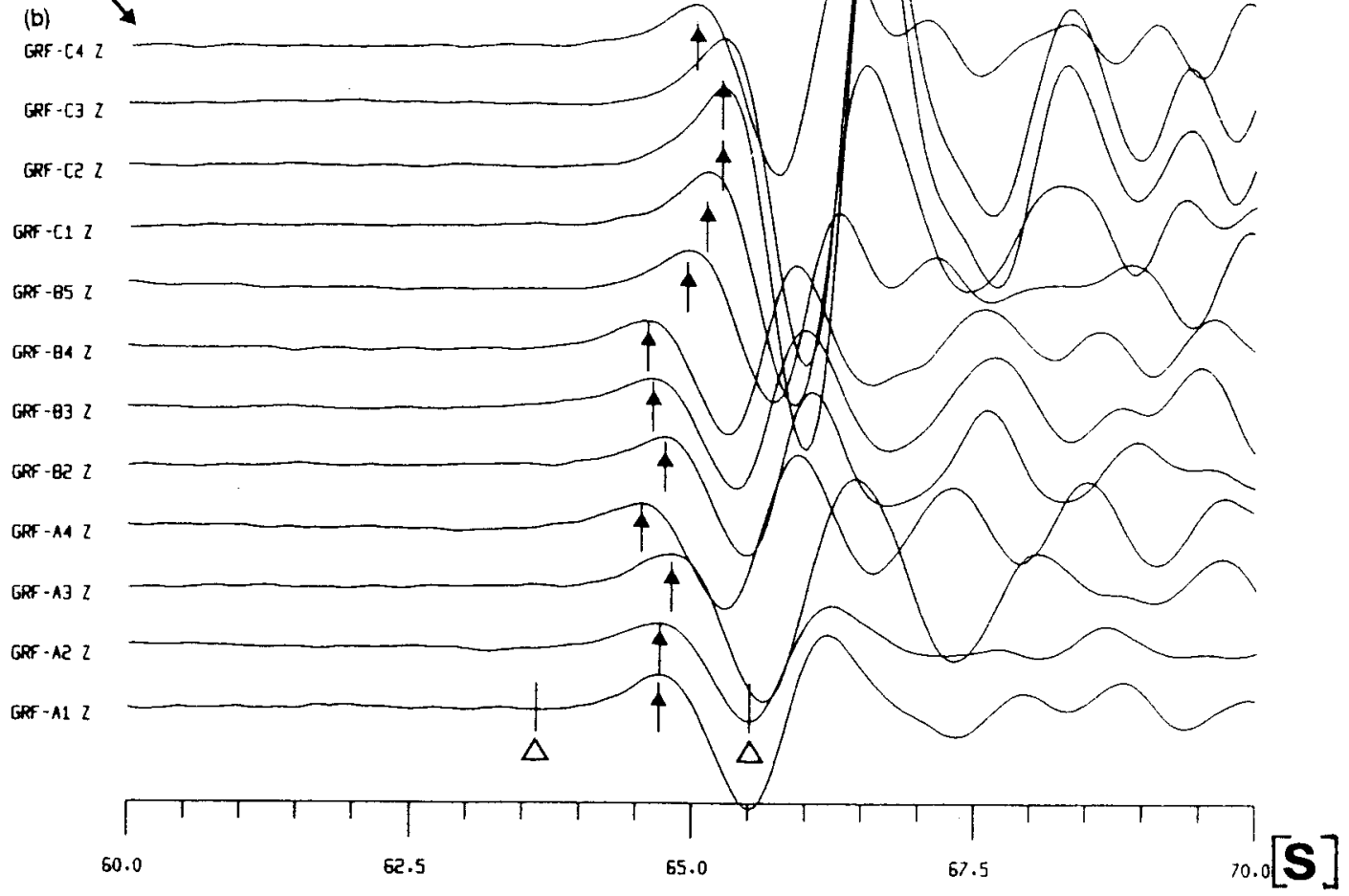

GRF + 990850-1146

Figure 4. WWSSN-SP filtered seismograms (vertical component) of the $P$ wave of two events at the GRF stations (A1-C4). The traces have been aligned according to the theoretical slowness and back azimuth of the $P$ wave. The time segment shown is $10 \mathrm{~s}$ long and the time window for the determination of the first coherent extremum is indicated by the two open triangles. The extremum in each trace within this time segment is given by the mark with the full triangle. The insert indicates the theoretical back azimuth of the two events. (a) Event in Bangladesh (slowness 6.4 s deg ${ }^{-1}$, back aximuth $83.7^{\circ}$ ). (b) Event in Ethiopia (slowness $7.9 \mathrm{~s} \mathrm{deg}^{-1}$, back azimuth $135.6^{\circ}$ ). 
$B P[1-4] H Z$

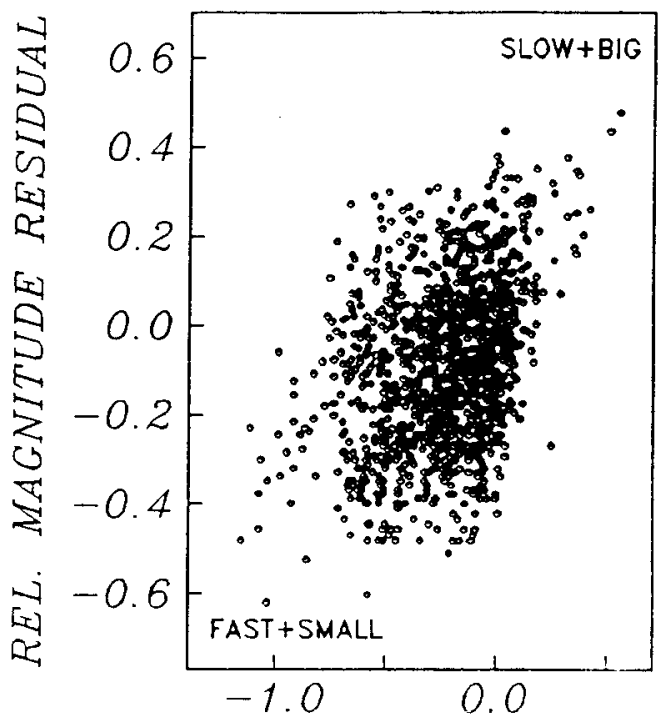

REL. TIME RESIDUAL [S]

\section{$B B-V E L$}

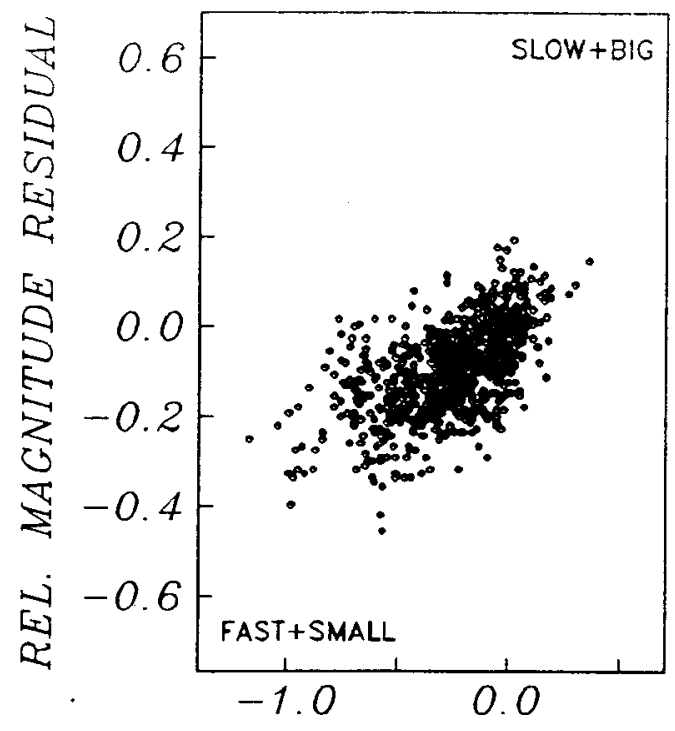

REL. TIME RESIDUAL [s]
$W W S S N-S P$

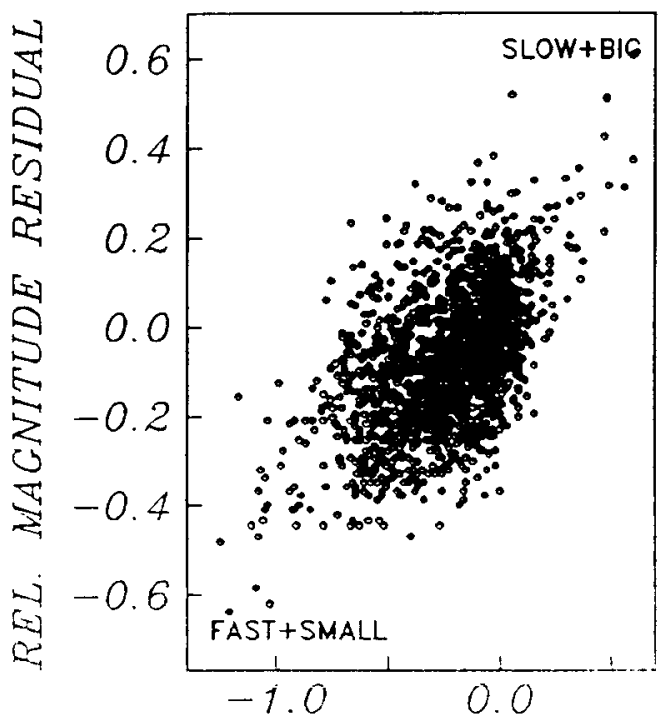

REL. TIME PESIDUAL [S]

WVSSN-IP

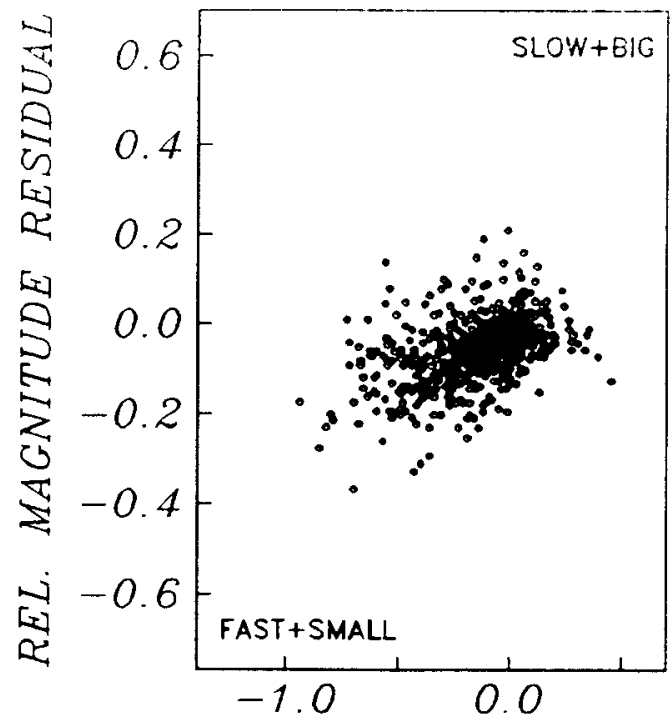

REL. TIME RESIDUAL [s]

Figure 5. Relative magnitude residual $\Delta M_{X}^{i}$ versus relative traveltime residual $\Delta T_{X}^{i}$ in seconds with respect to the reference station Al for all GRF stations $X$ (Fig. 1) and all events $i$ (Fig. 2) for the four filters (Fig. 3) indicated at the top of each figure. Note the trend of negative (fast) traveltimes for negative magnitudes (small amplitudes). 
(BB-VEL and WWSSN-LP) the amplitude residuals decrease more strongly than the traveltime residuals and that the scatter of $\Delta M_{X}^{i}, \Delta T_{X}^{i}$ is reduced.

\subsection{Average relative amplitude versus traveltime residuals}

Station averages $\Delta M_{X}^{\mathrm{av}}, \Delta T_{X}^{\mathrm{av}}$, i.e. the average over the relative $\Delta M_{X}^{i}, \Delta T_{X}^{i}$ values of all events recorded at an individual station $X$, are given in Fig. 6. These values represent a static correction for traveltime and amplitudes. Because they average over all events, i.e. all back azimuths and distances (Fig. 2), they are mainly influenced by shallow near-receiver structure.

The general trend of the residuals in Fig. 6 shows a slope of approximately 0.25 units $\mathrm{s}^{-1}$. An almost linear relation between $\Delta M_{X}^{\mathrm{av}}$ and $\Delta T_{X}^{\mathrm{av}}$ becomes especially clear for BB-VEL and WWSSN-LP. For these two low-frequency bands the scatter of the $\Delta M_{X}^{\mathrm{av}}, \Delta T_{X}^{\mathrm{av}}$ values within the three clusters and the standard deviation (error bars) at individual stations is also reduced. That the differences in the residuals between the four frequency bands are not due to the different numbers of events was checked by determining $\Delta M_{X}^{\mathrm{av}}, \Delta T_{X}^{\mathrm{av}}$ values for subsets of the 158 events, i.e. the 128, 72 and 57 events shown in Fig. 2.

The four frequency bands show consistent features and trends. For all stations fast arrivals (negative traveltime residuals) correlate with small amplitudes (negative magnitude residuals). Three clusters with similar $\Delta M_{X}^{\text {av }}$, $\Delta T_{X}^{\text {av }}$ values can be identified in Fig. 6: cluster A (stations $\mathrm{A} 2+\mathrm{A} 3$ ), cluster $\mathrm{B}$ (stations $\mathrm{A} 4+\mathrm{B} 1+\mathrm{B} 2+\mathrm{B} 3+\mathrm{B} 4$ ), except for the BP filter where $B 2$ is an outlier, and cluster $C$ (stations $\mathrm{C} 1+\mathrm{C} 3+\mathrm{C} 4$ ). Station $\mathrm{B} 5$ is between cluster $\mathrm{B}$ and $\mathrm{C}$ and station $\mathrm{C} 2$ has a large traveltime residual but only a small amplitude residual. The location of the stations and the clusters on the Franconian Jura is given in Fig. 7(a). The $\Delta M_{X}^{\mathrm{av}}, \Delta T_{X}^{\mathrm{av}}$ clustering correlates with the location of the stations, i.e. the $\Delta M_{X}^{\mathrm{av}}, \Delta T_{X}^{\mathrm{av}}$ clusters are also geographically grouped, station B5 is situated between cluster B and $\mathrm{C}$ and station $\mathrm{C} 2$ is the most south-westerly station.

The correlation between the $\Delta M_{X}^{\mathrm{av}}, \Delta T_{X}^{\mathrm{av}}$ values in Fig. 6 and the geographical distribution of the stations and clusters in Fig. 7(a) suggests local anomalies as reasons for at least a large part of the station averages. This assumption is strengthened by the observation, that the traveltime residuals $\Delta T_{X}^{\text {av }}$ decrease with the increase in thickness of the low-velocity sedimentary wedge under the GRF array (Fig. 7 b; Krüger \& Weber 1992, Fig. 5). The stations in the south-south-west (C cluster) are situated on thinner low-velocity sediment layers than the stations in the north-north-east near $\mathrm{A} 1$ and show, therefore, negative (fast) relative traveltime residuals. The near-surface effects, i.e. the change in thickness of the sediments, gives about 50 per cent of the traveltime residual at the $\mathrm{C}$ cluster (Krïger \& Weber 1992). That tectonic structures might also play an important role can be seen by the offsets of about $0.1 \mathrm{~s}$ in the two regions where the main faults intersect the Franconian Jura (Figs $7 b$ and c). The full triangle indicates the Bayrischer Pfahl and the open triangle the DonauRandbruch. These tectonic features are still active (occurrence of earthquakes with $M_{L}$ up to 5.0 under the C cluster, Leydecker 1986). The remaining 50 per cent of the traveltime residuals could be explained by a velocity increase in the crust and the uppermost mantle under the array from north to south (see, e.g. Faber et al. 1986, Figs 9 and 10$)$.

Whereas Faber et al. (1986), Nixdorf (1986) and Krüger \& Weber (1992) used only the traveltime information to analyse the structure under the array, the next section studies the influence of the near-surface structure under the stations on traveltime and amplitude.

\section{INTERPRETATION}

\subsection{Site effects}

For the determination of 1-D models of the near-surface layers under the array information from local and regional geology (Geologische Karte von Bayern 1:500,000,1981) is used together with results from boreholes (Schmidt-Kaler 1969, 1985; Gudden 1970, 1981, 1982, 1989; Bader 1982a; Salger \& Schmid 1982; Schmid 1982; Gudden \& Schmid 1985), local refraction studies (Breyer 1956, 1972; Bader $1982 \mathrm{a}, \mathrm{b}$; Stein 1985,1989 ) and a polarization analysis of $P$ waves (Krüger 1994). The general feature is a wedge of low-velocity sediments with increasing thickness towards the north-north-east between the surficial high-velocity top layer of limestone and the top of the granite basement with a dip of about $0.8^{\circ}$ towards the north-north-east (Krüger \& Weber 1992). Models for stations A1, C2 and the clusters $\mathrm{A}, \mathrm{B}$, and $\mathrm{C}$ (Fig. 7a) are given in Fig. 8. Other examples of low-velocity sediments in south-east Germany can be found in, e.g. Greiner \& Lohr (1980). Since the information on the structure under the array is based on methods operating in very different frequency bands, e.g. seismic borehole measurements versus polarization studies (Krüger 1994), the models shown in Fig. 8 should only be considered as the best, 1-D representations of the local structure. This is especially true for the clusters; but since these models are used to determine the effect of the azimuthal- and distance-independent term (station average) such a simplification seems justified.

A comparison of the observed relative magnitude and traveltime residuals of these clusters $\left(\Delta M_{\text {cluster, }}^{\text {av }}, \Delta T_{\text {cluster }}^{\text {av }}\right)$ with the theoretical results for the models given in Fig. 8 is shown in Fig. 9. The stars are the data with standard variation. The circles are the corresponding theoretical values determined from synthetic seismograms computed with the reflectivity method (Fuchs \& Müller 1971; Müller 1985) for a plane-wave incident from below, with an angle of incidence corresponding to a source at $70^{\circ}$ distance. The frequency of the source wavelet used in the synthetics was determined from the data. For the short-period filters (BP and WWSSN-SP) the models are able to explain about 50 per cent of the observed traveltimes; note also the agreement with the ray-theoretical traveltime residuals, and almost 100 per cent of the amplitude anomalies. This shows that the near-surface effects play a dominant role for the average amplitude and traveltime anomalies observed at the array. That such resonance phenomena are strongly site and frequency dependent can be seen by the differences between the $\Delta M_{\text {cluster }}^{\mathrm{av}}, \Delta T_{\text {cluster }}^{\mathrm{av}}$ values for the different frequency bands (Fig. 9) (see also Liu \& Kind 1986, for the effect of varying thickness of sedimentary layers). 

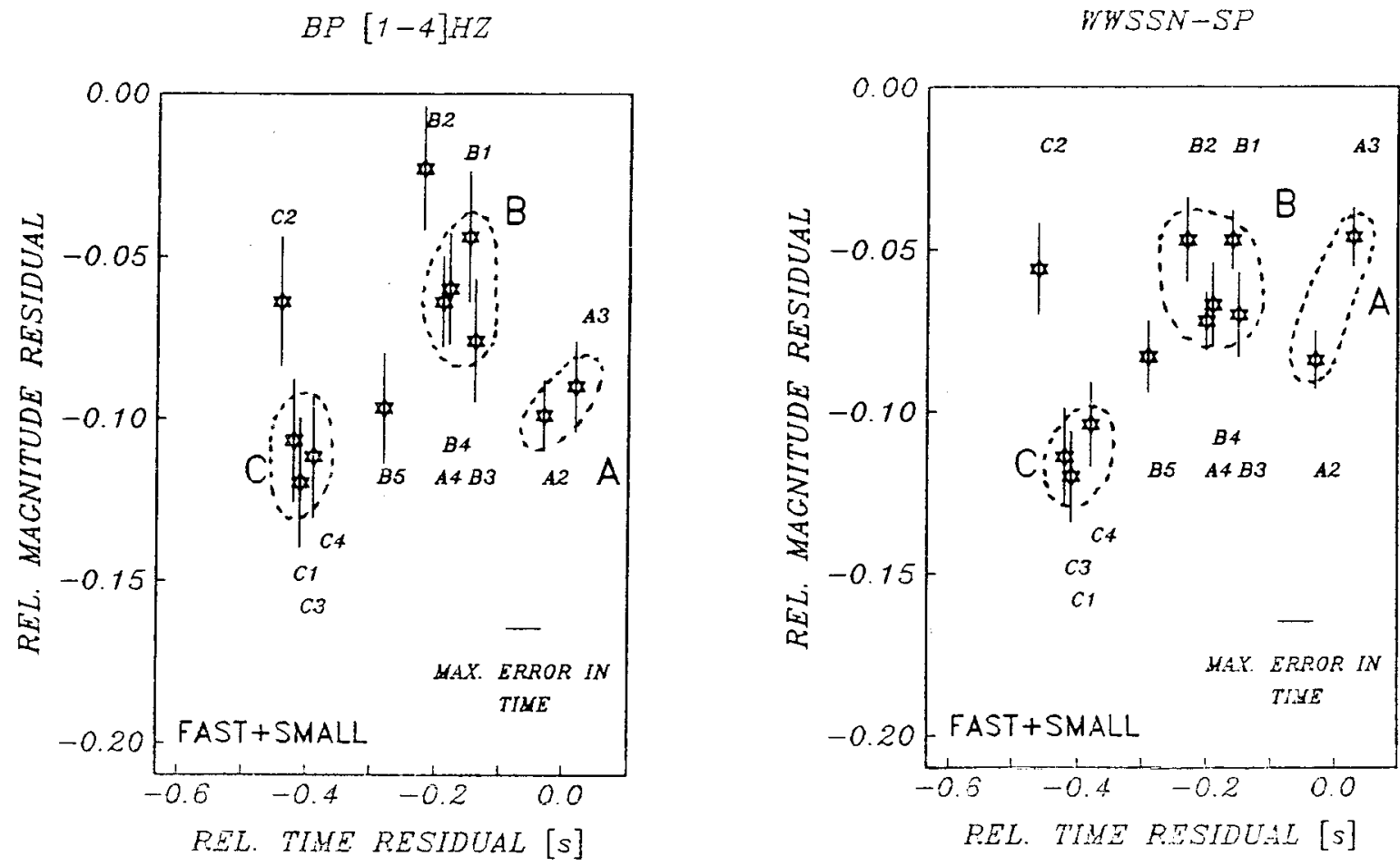

$B B-V E L$

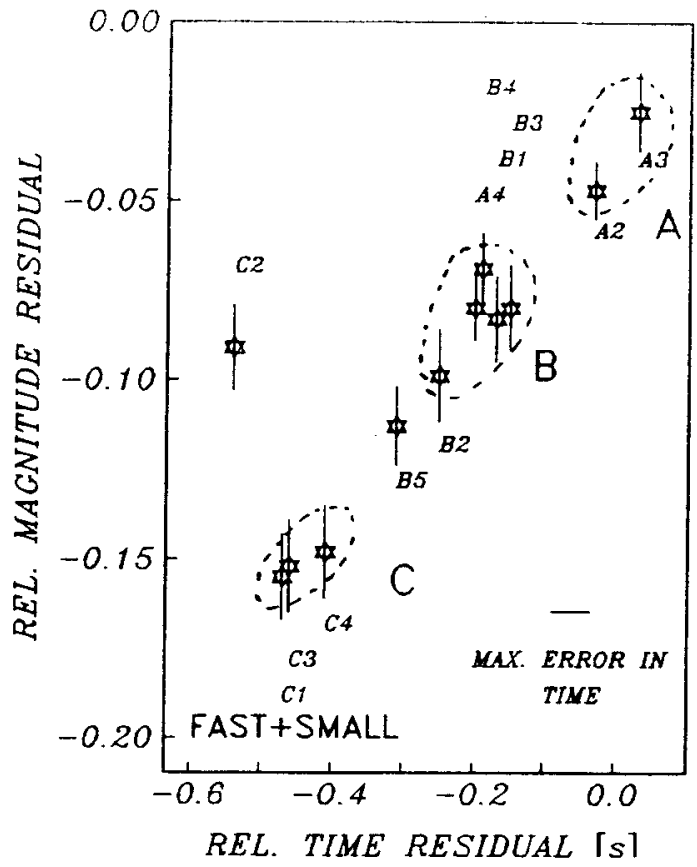

WWSSN-LP

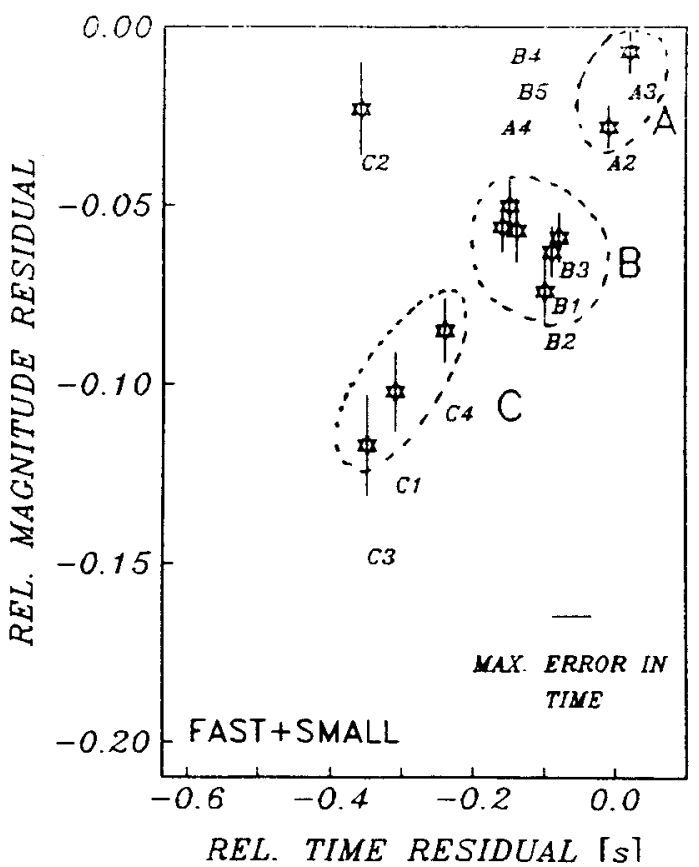

Figure 6. Relative magnitude residual $\Delta M_{X}^{\text {av }}$ versus relative traveltime residual $\Delta T_{X}^{\text {av }}$ for the average over all events recorded at each of the GRF stations for four filters (stars; with standard deviation). Clusters of stations with similar $\Delta M_{X}^{\mathrm{av}}, \Delta T_{X}^{\text {av }}$ values are indicated by dashed lines. 


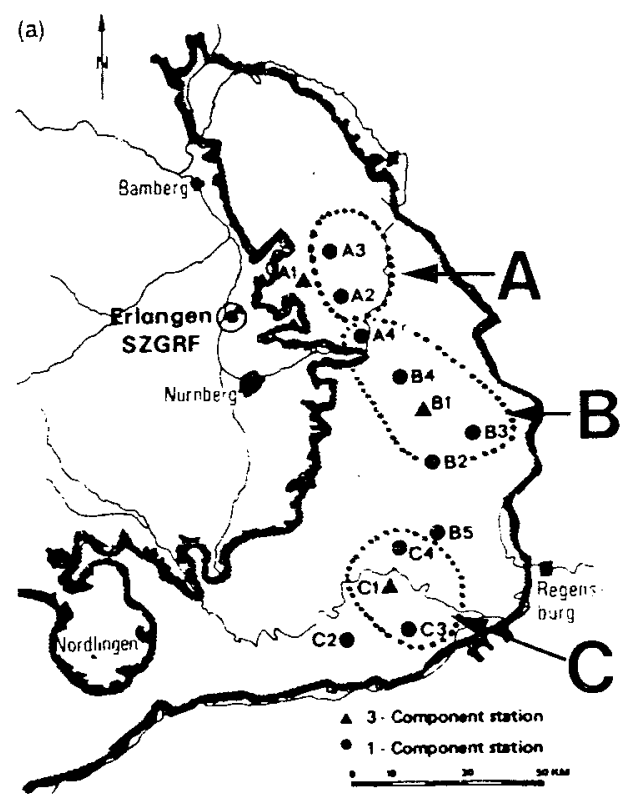

$B P[1-4] H Z$

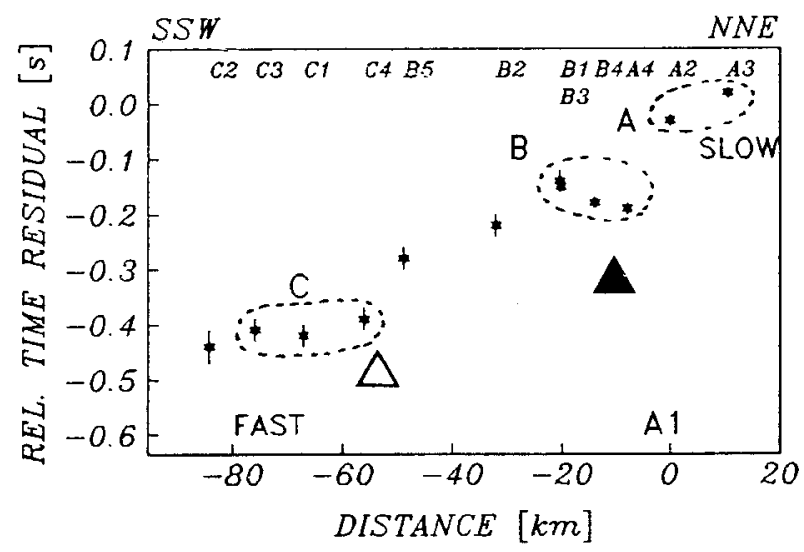

$B B-V E L$

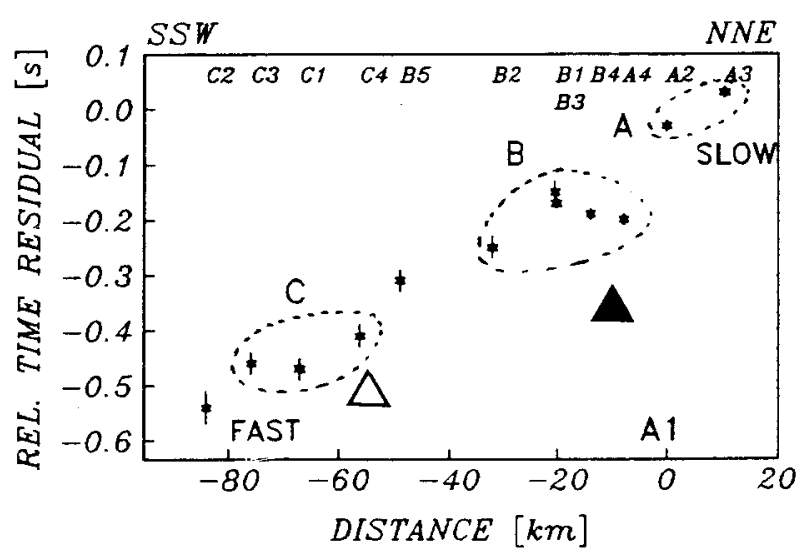

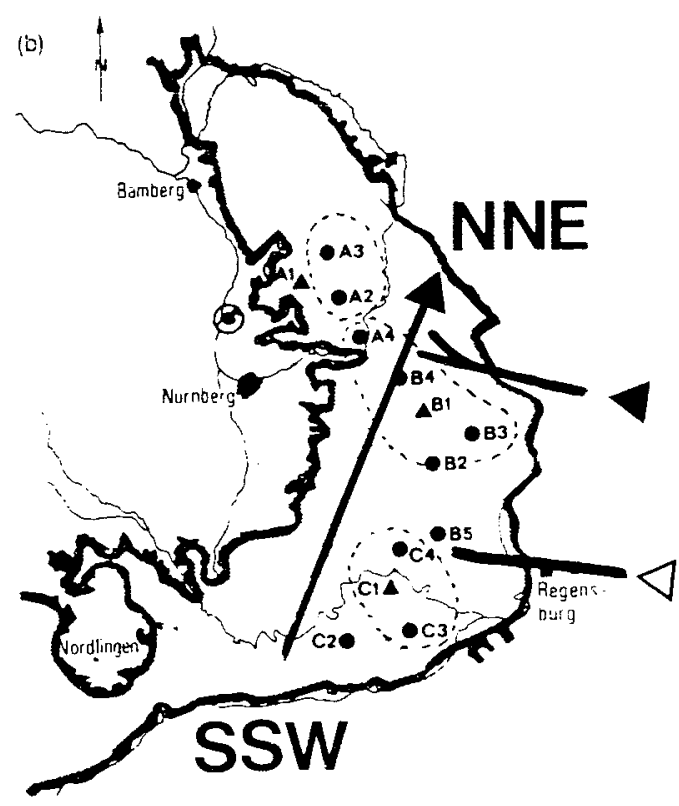

(c)
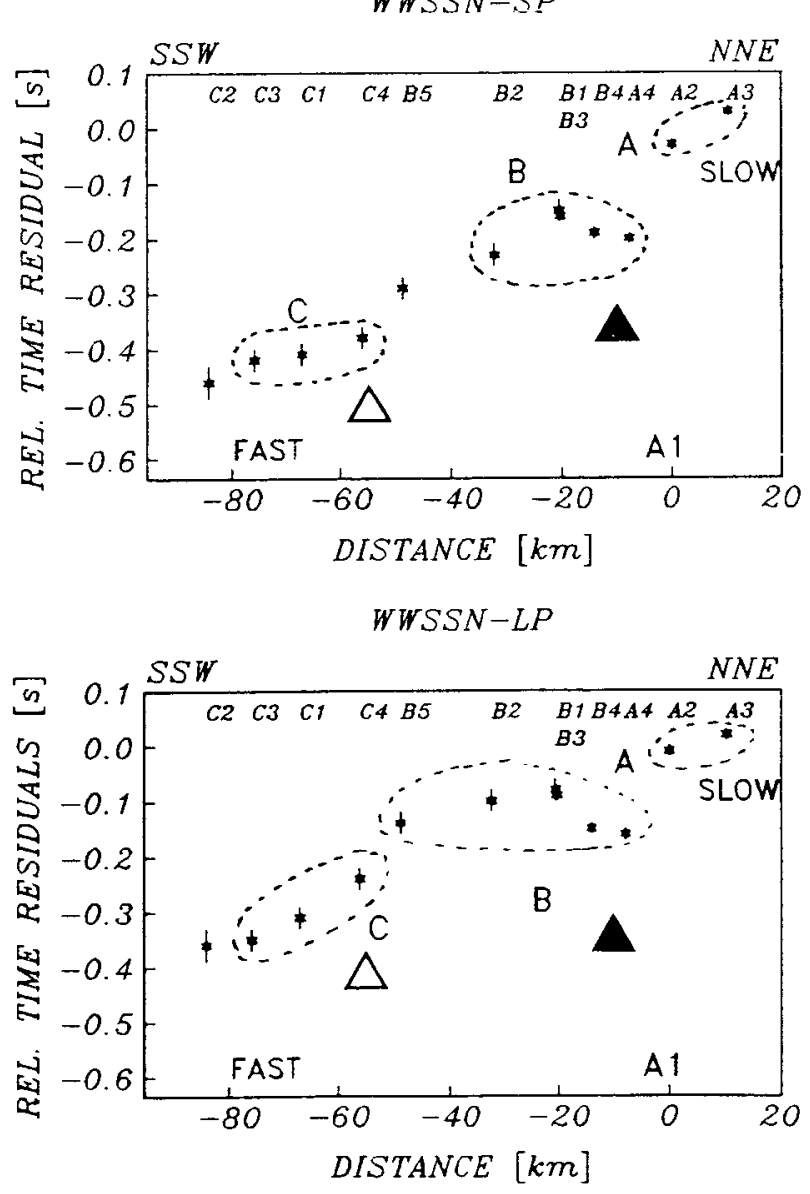

Figure 7. (a) Distribution of clusters of GRF stations with similar $\Delta M_{X}^{a v}, \Delta T_{X}^{\text {av }}$ values (see also Fig. 6). (b) Location of GRF stations. The arrow indicates the dip of the sedimentary wedge under the GRF array. The solid lines marked by an open and full triangle are the main fault systems visible at the surface. (c) $\Delta T_{X}^{\text {av }}$ versus distance from station $A 1$ in a SSW-NNE direction (b) for the GRF stations and four filters (stars; with error bars). The open and full triangles indicate the location where the main faults intersect the Franconian Jura. 

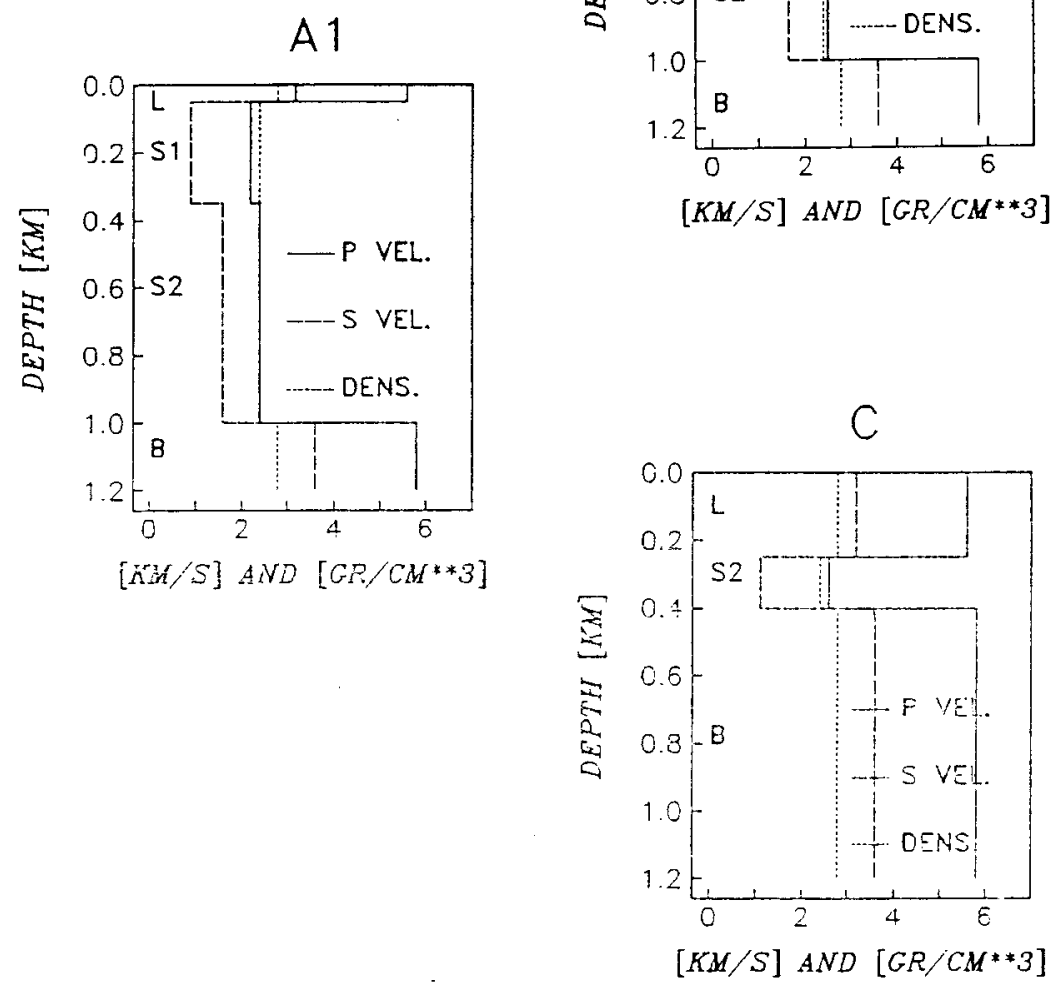

$[K M / S] A N D\left[G R / C M^{* *}\right]$
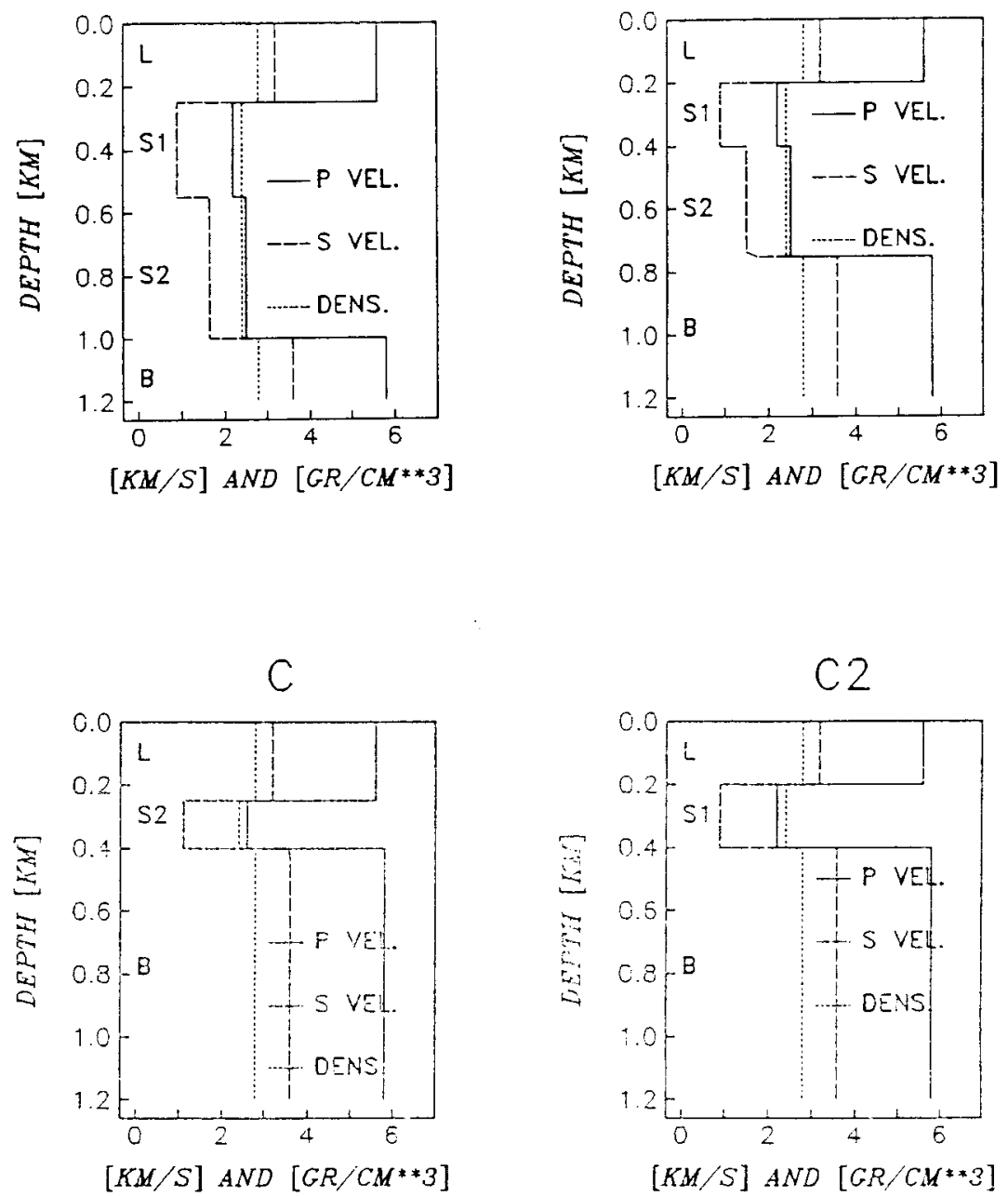

Figure 8. Density, $P$ - and $S$-velocity models of the near-surface structure for the reference station A1, clusters A, B, C and station C2. L indicates the limestone, $S$ the sediments and $B$ the basement.

For low frequencies (WWSSN-LP) the near-surface layers become almost transparent (see synthetic results in Fig. 9). Therefore the data for this filter show mostly the influence of deeper anomalies. The other frequency bands exhibit almost the same mismatch between the observed and theoretical $\Delta M_{\text {cluster }}^{\text {av }}, \Delta T_{\text {cluster }}^{\mathrm{av}}$ values as in the WWSSN-LP filter. This suggests that about 50 per cent of the average relative traveltime residual across the array originates from inhomogeneities in crust and/or lithosphere under the array (for models see, e.g. Aichele 1976; Giese 1976; Faber et al. 1986; Nixdorf 1986; Plomerová \& Babuška 1988).

The other half of the observed average traveltime residuals and almost all of the average amplitude residuals are produced by the near-surface structure in the topmost kilometre. That these shallow structures can play an important role for the magnitude residuals agrees with the observation of strong amplitude effects due to local, near-surface geology (Nakanishi \& Motoya 1990; Mori \& Frankel 1992; see also Cranswick 1988; Cranswick et al. 1990; Aki 1993).

\subsection{Regional effects}

If the observed station average is removed from the relative traveltime and amplitude residuals, strong azimuthal- and distance-dependent patterns can be observed at the different stations of the array. Fig. 10(a) (Fig. 10b) gives $\Delta T_{X}^{i-a v}$ $\left(\Delta M_{X}^{i-a v}\right)$, i.e. the relative traveltime (magnitude) residuals for individual events $\Delta T_{X}^{i}\left(\Delta M_{X}^{i}\right)$ after the subtraction of the station averages $\Delta T_{X}^{\text {av }}\left(\Delta M_{X}^{\text {av }}\right)$, for the WWSSN-SP filter. Within three groups of stations (clusters) the patterns of the residuals in Fig. 10 are very similar. The cluster $A^{\prime}$ consists of stations $\mathrm{A} 3+\mathrm{A} 2+\mathrm{A} 4$, cluster $\mathrm{B}^{\prime}$ of stations $\mathrm{B} 4+\mathrm{B} 1+\mathrm{B} 3+\mathrm{B} 2$ and cluster $\mathrm{C}^{\prime}$ of stations $\mathrm{C} 4+\mathrm{B} 5+$ $\mathrm{C} 2+\mathrm{C} 1+\mathrm{C} 3$. The location of these clusters is given in Fig. 11. In constrast to Fig. 7(a), where stations $B 5$ and $C 2$ are outliers, the traveltime and magnitude residual patterns in Fig. 10 are more consistent. As before a correlation of fast (slow) traveltime residuals with small (large) magnitude residuals can be observed.

As expected, the traveltime residuals $\Delta T_{\mathrm{X}}^{i-\mathrm{av}}$ for cluster 
$B P[1-4] H Z$

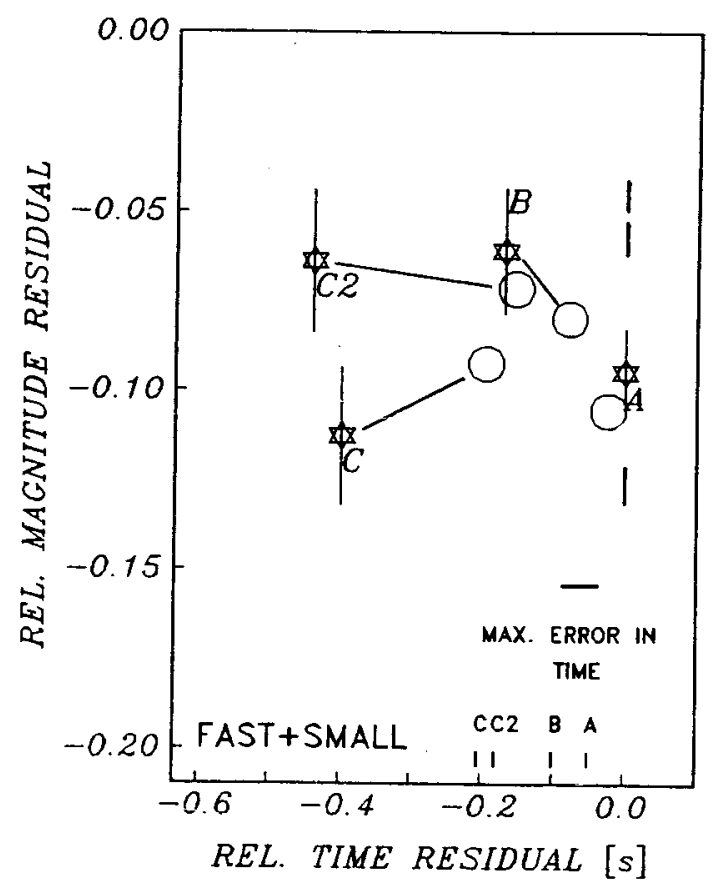

$B B-V E L$

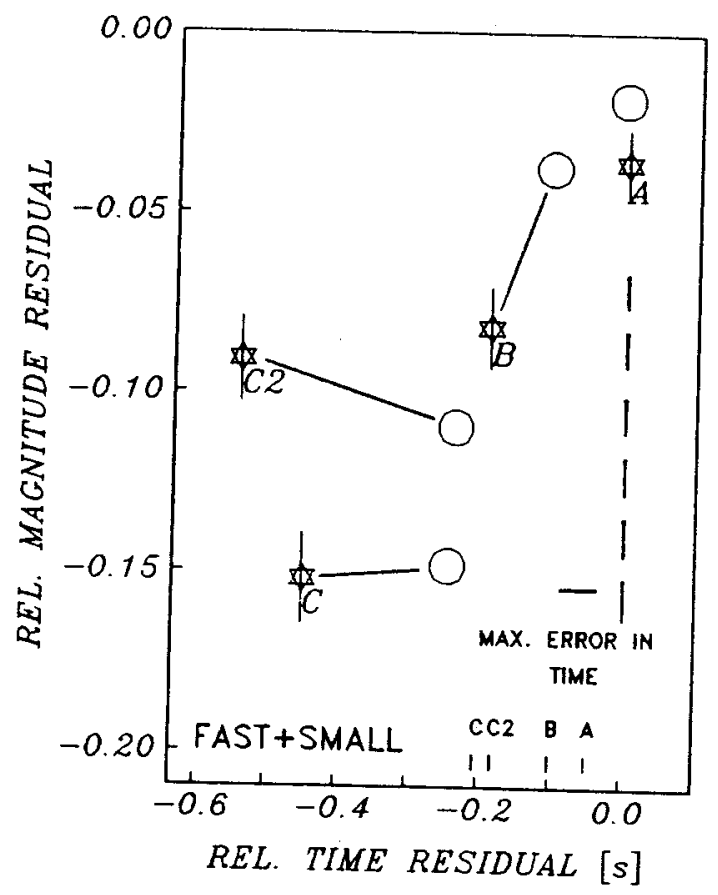

WWSSN-SP

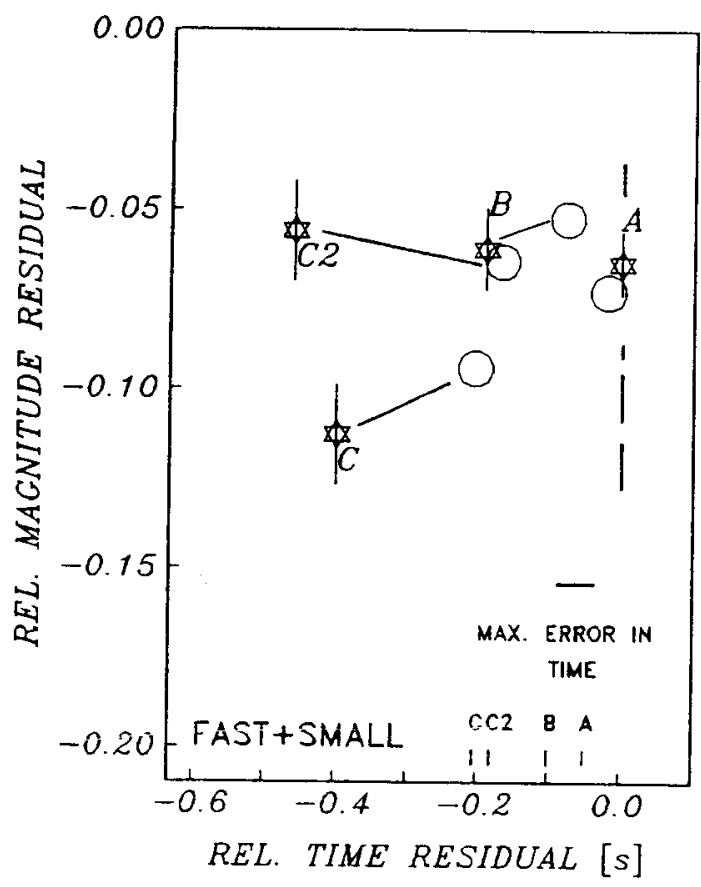

$W W S S N-L P$

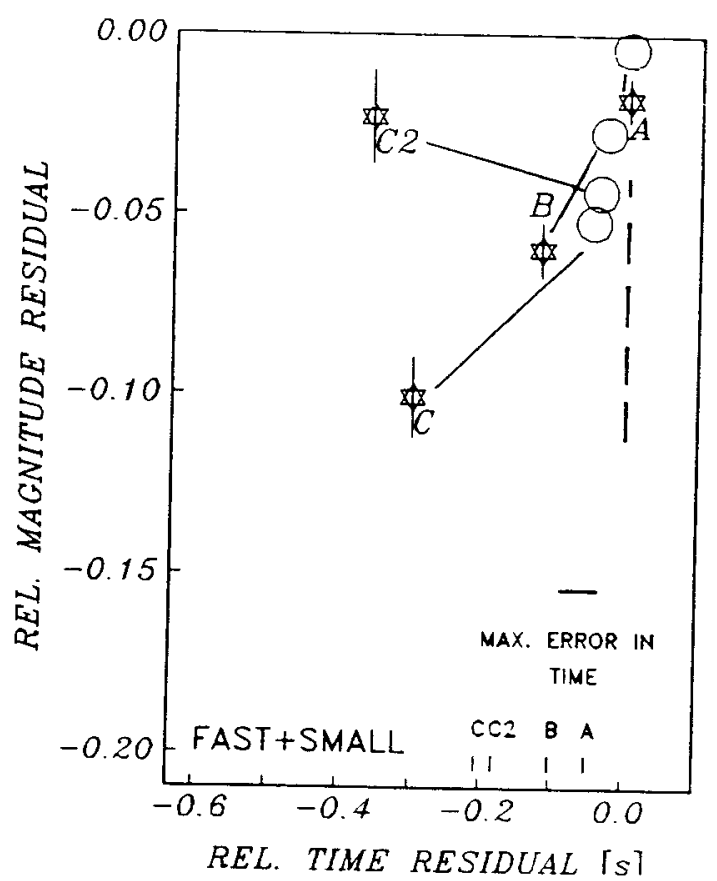

Figure 9. Observed $\Delta M_{\text {cluster }}^{\text {av }}$ versus $\Delta T_{\text {cluser }}^{\text {av }}$ for the clusters A, B, C and station C2 for four filters (stars; with standard deviation). The open
circles are the corresponding theoretical values for circles are the corresponding theoretical values for the models given in Fig. 8 . The ray-theoretical traveltime residuals for these models are
given by the small vertical bars at the bottom of each figure. 


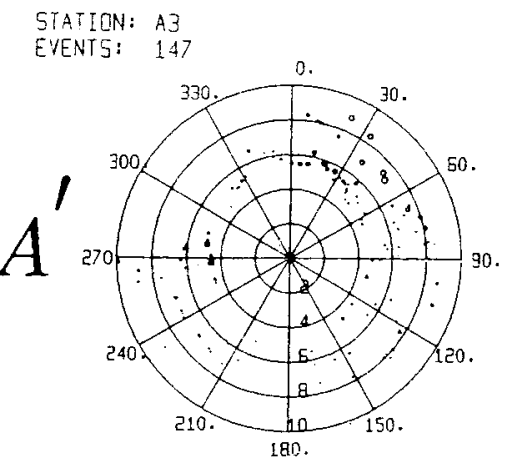

STATION: AC

EVENTS: 155

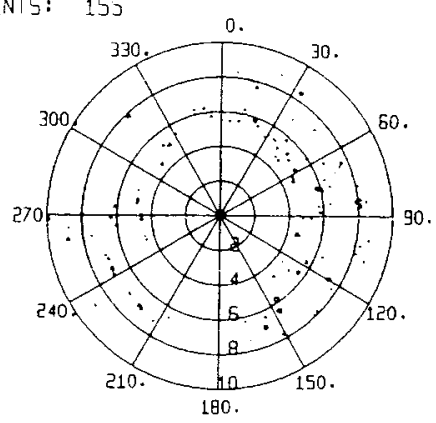

STAIION: AA

EVENTS: $1390-0.3$

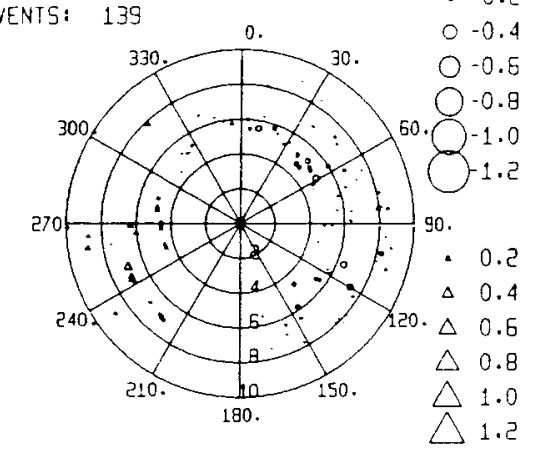

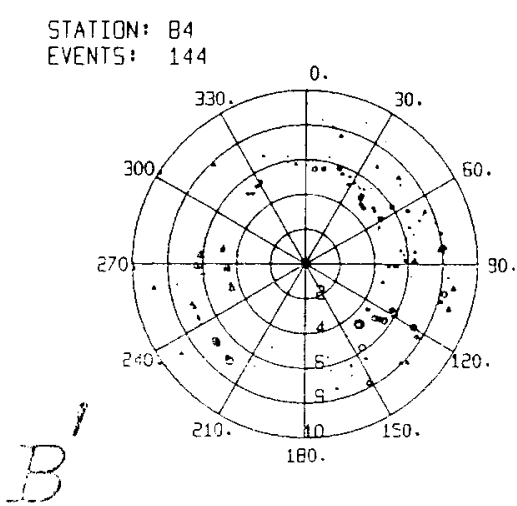

STATION: 81
EVENTS: 134

330.0.

\section{STATION: 83}

EVENTS: 149
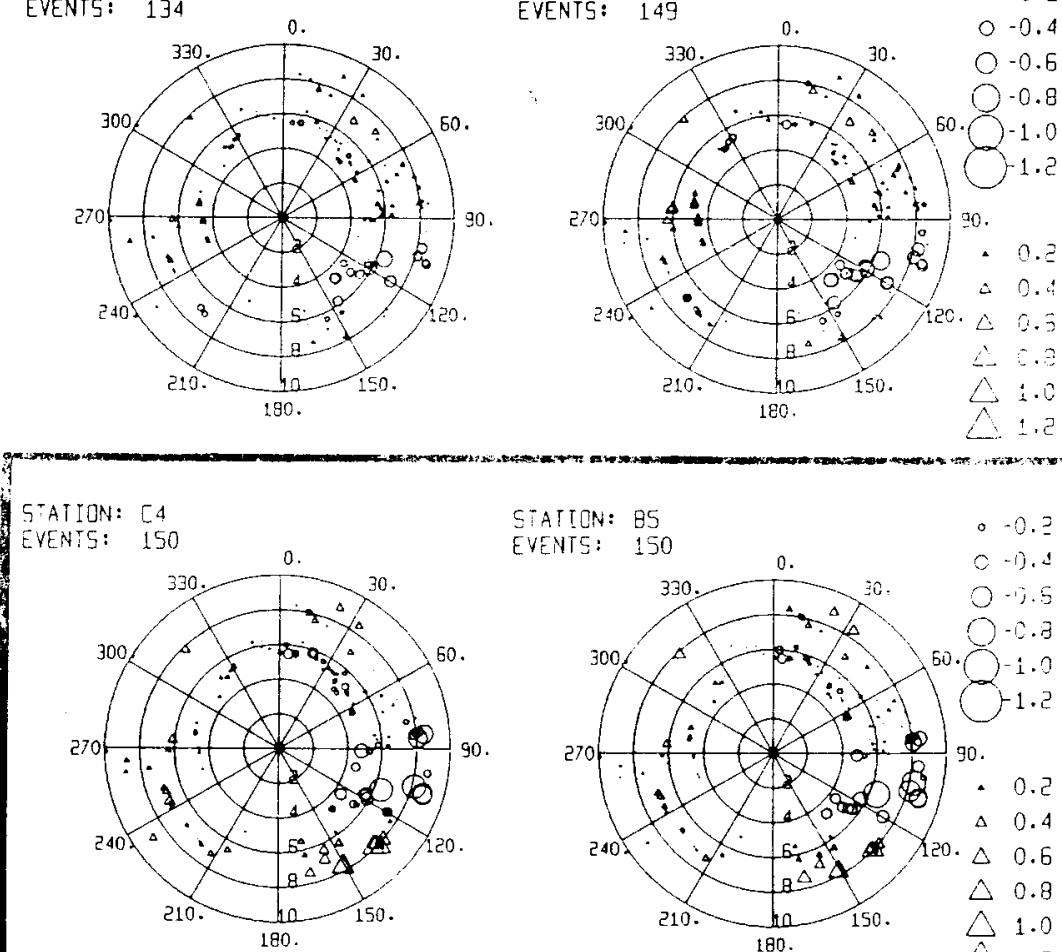

STATION: 85

EVENTS: 150

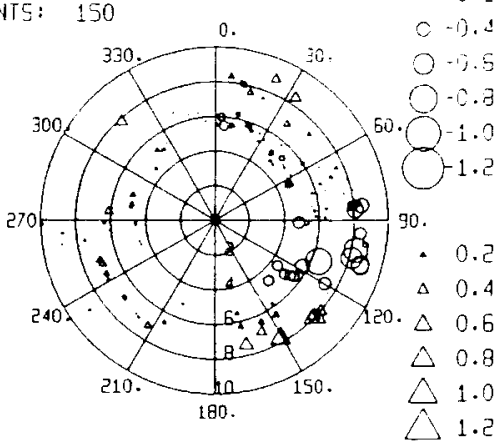

STATION: CI

EVENTS: 136

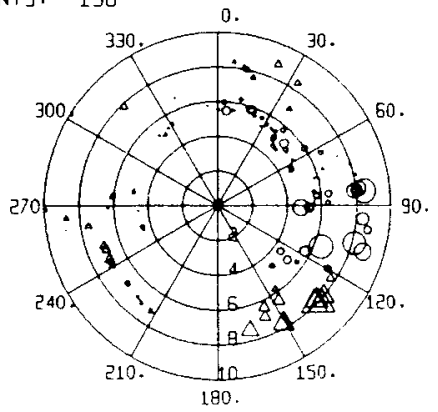

STAIION: 63

EVENTS: 151

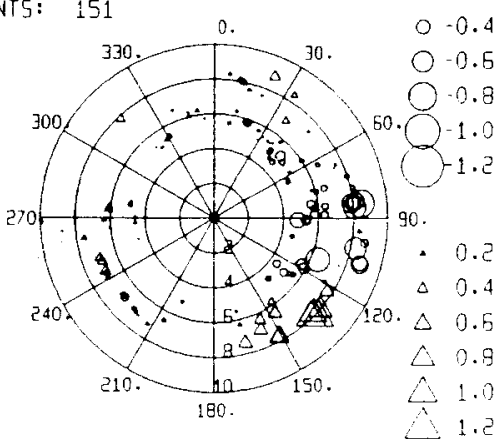

Figure 10. Relative traveltime residuals $\Delta T_{X}^{i-\mathrm{av}}$ in seconds as a function of back azimuth (in degrees) and slowness (in $s$ deg ${ }^{-1}$, radial component), i.e. $\Delta T_{X}^{i}$ (Fig. 5) after the removal of the site effect $\Delta T_{X}^{a v}$ (Fig. 6). The relative residuals are given for the events of the WWSSN-SP filter (Fig. 2b) at 12 stations. The station, the number of the events used at each station and the three clusters $A^{\prime}, B^{\prime}$ and $C^{\prime}$ are also indicated: $(O)$ are fast traveltime residuals and $(\Delta)$ are slow traveltime residuals. (b) As for (a) but for the relative magnitude residuals $\Delta M_{X}^{i-a v}$, i.e. $\Delta M_{X}^{i}$ after the removal of the site effect $\Delta M_{X}^{\text {av }}$, for the WWSSN-SP filter: (O) are small-magnitude residuals and ( $\triangle$ ) are large-magnitude residuals. (c) As for (b) but for the WWSSN-LP filter. 

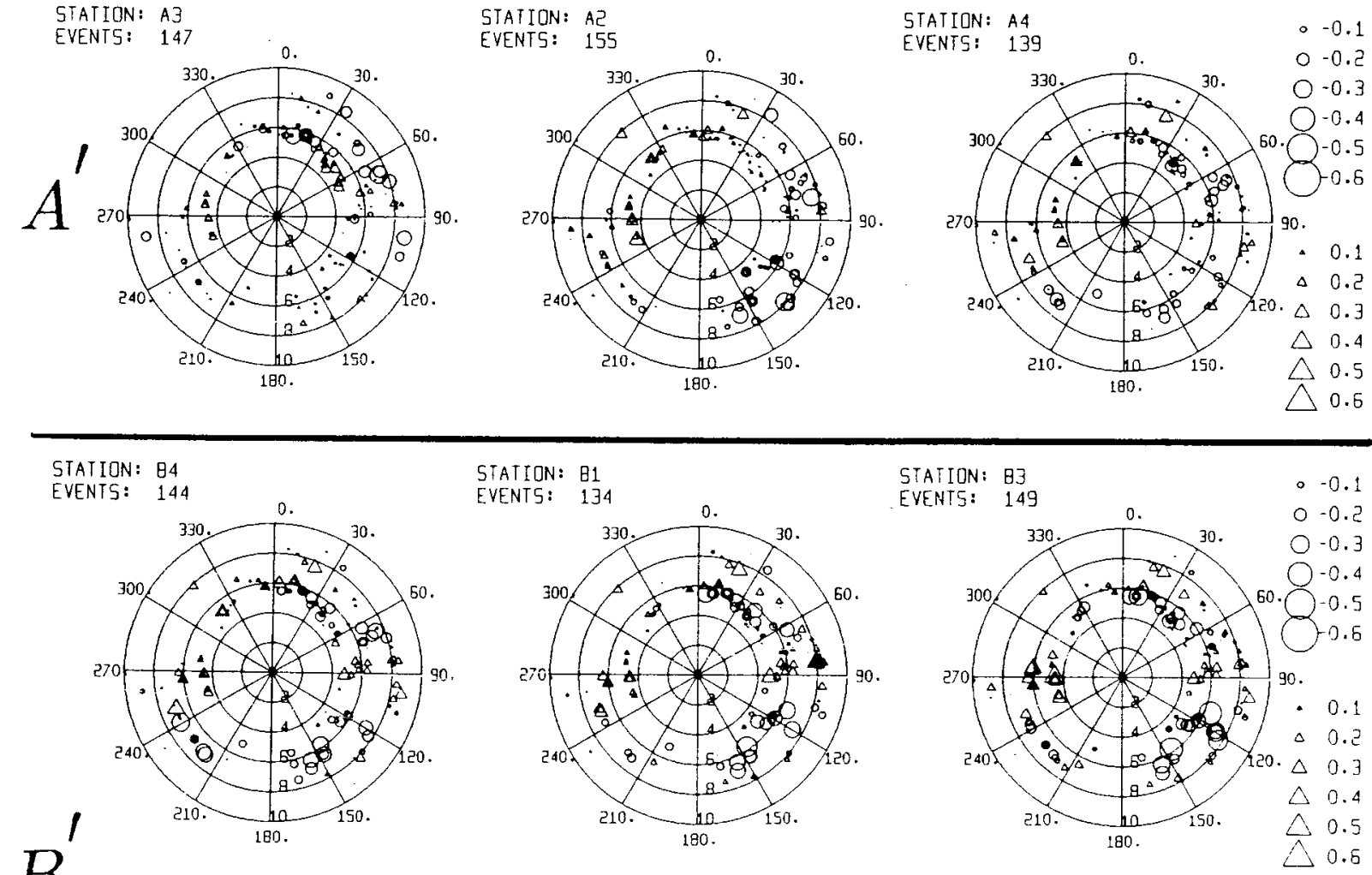

$B$

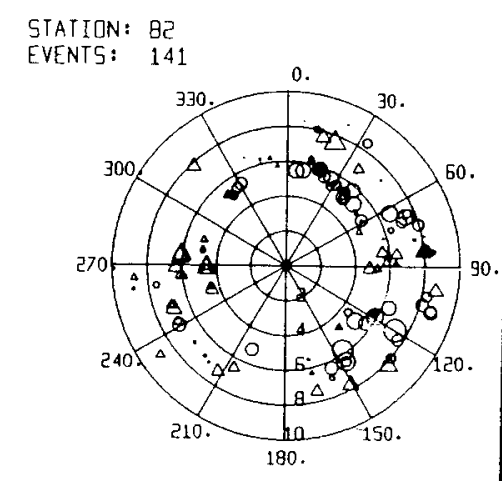

STATION: $[4$

EVENTS: 150

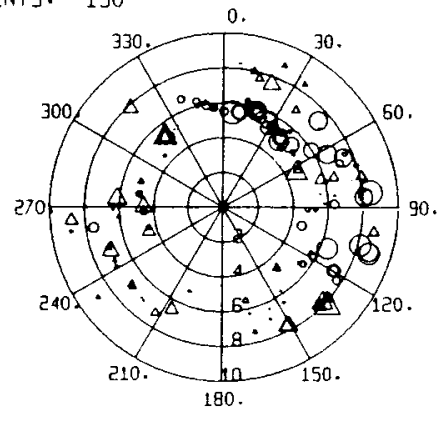

STATION: 85

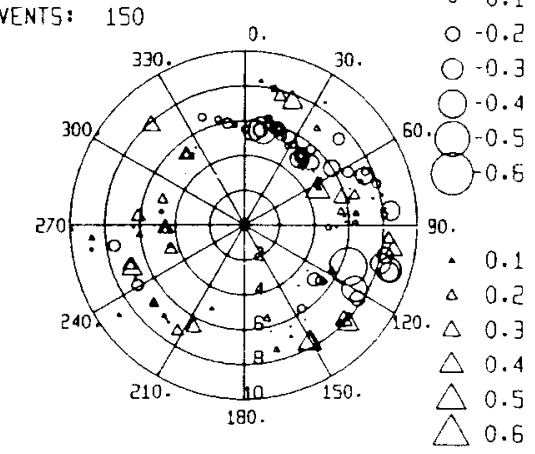

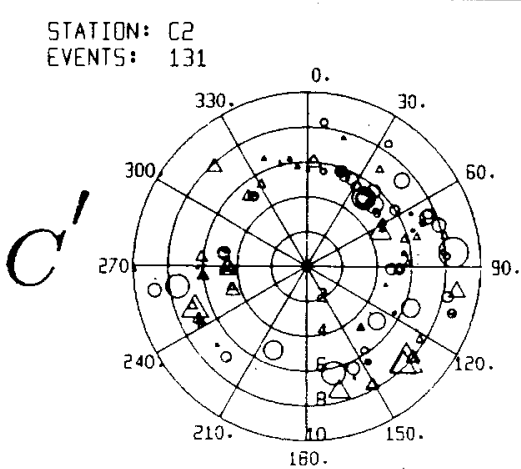

$\begin{array}{ll}\text { STATION: } & \text { C1 } \\ \text { EVENTS: } & 136\end{array}$

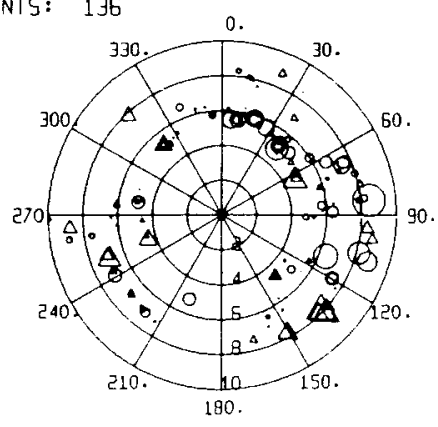

STATION: 23

EVENTS: 151

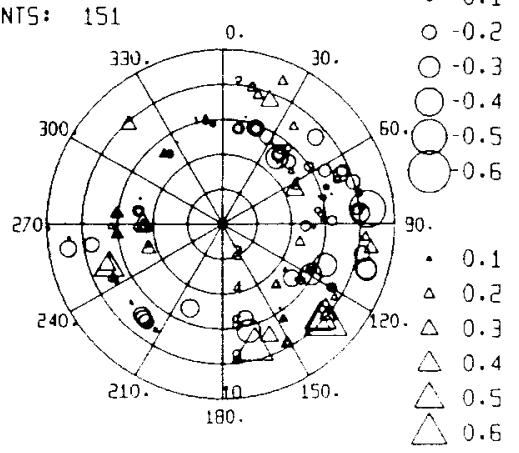

Figure 10. (Continued.) 


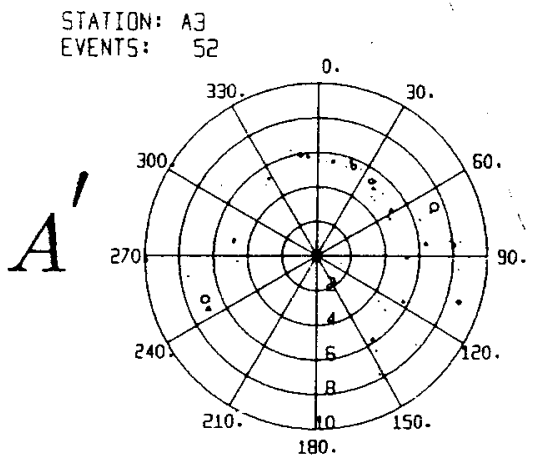

STATION: A2

EVENTS: 55

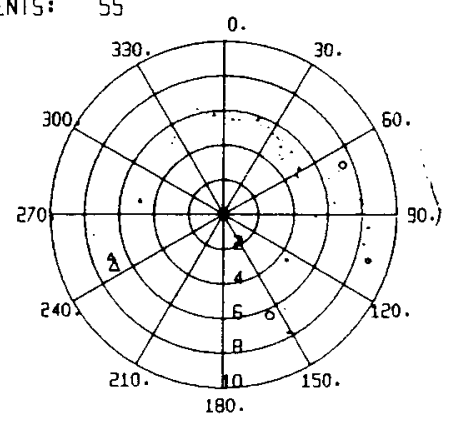

STATION: A4

$0-0.1$
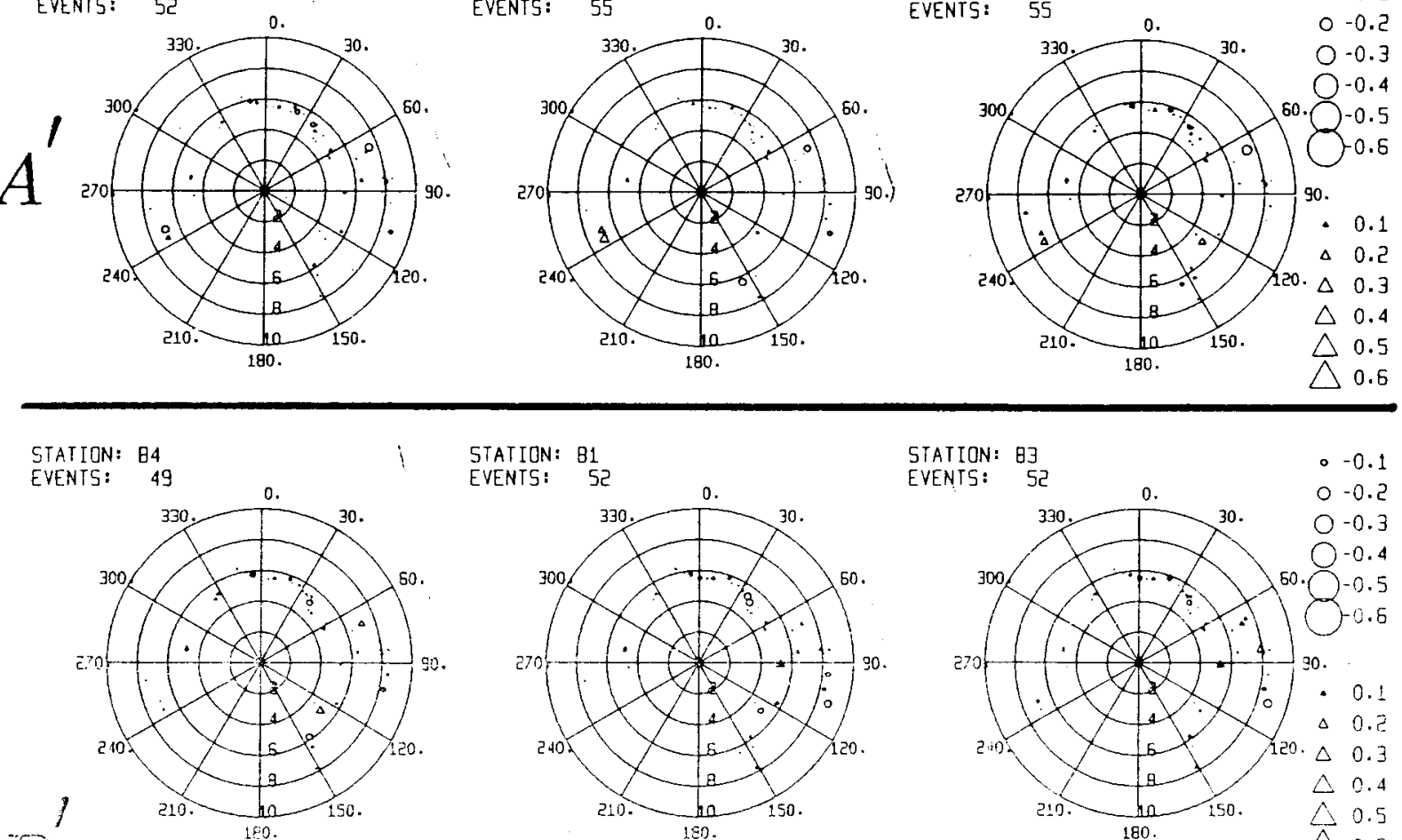

STATION: 81

EVENTS: 52

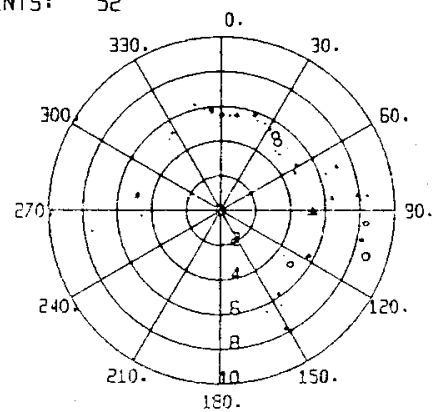

STATION: $\quad$ 㔭
EVENTS: 52

$0-0.1$

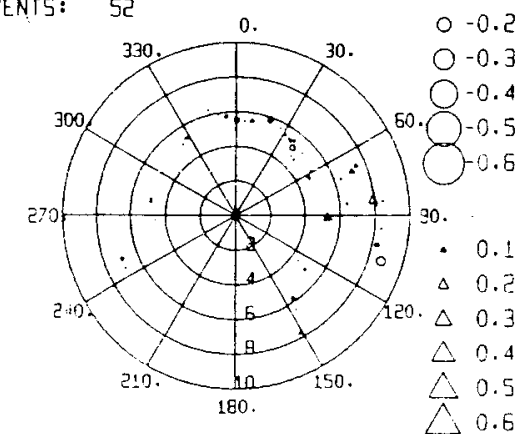

$B^{\prime}$

STATID: 85
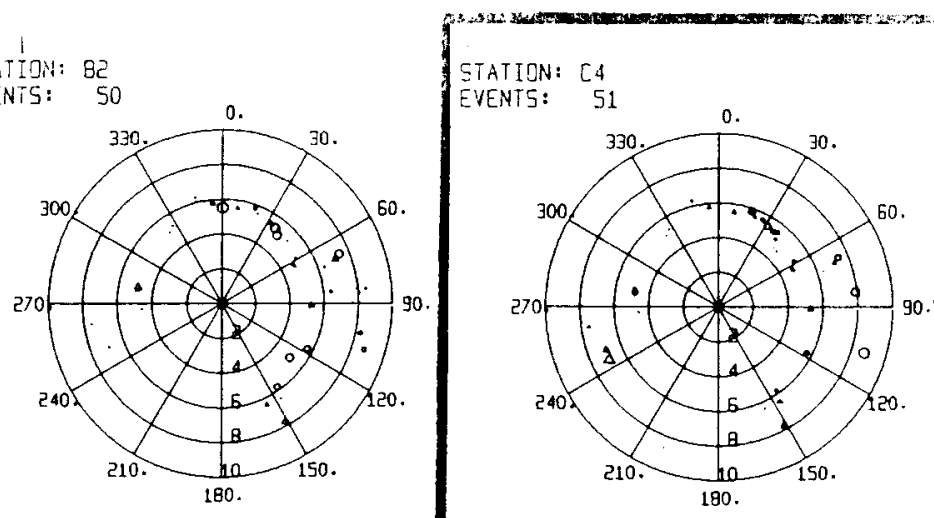

STATICN: 85

$53 \quad 0.0 .1$
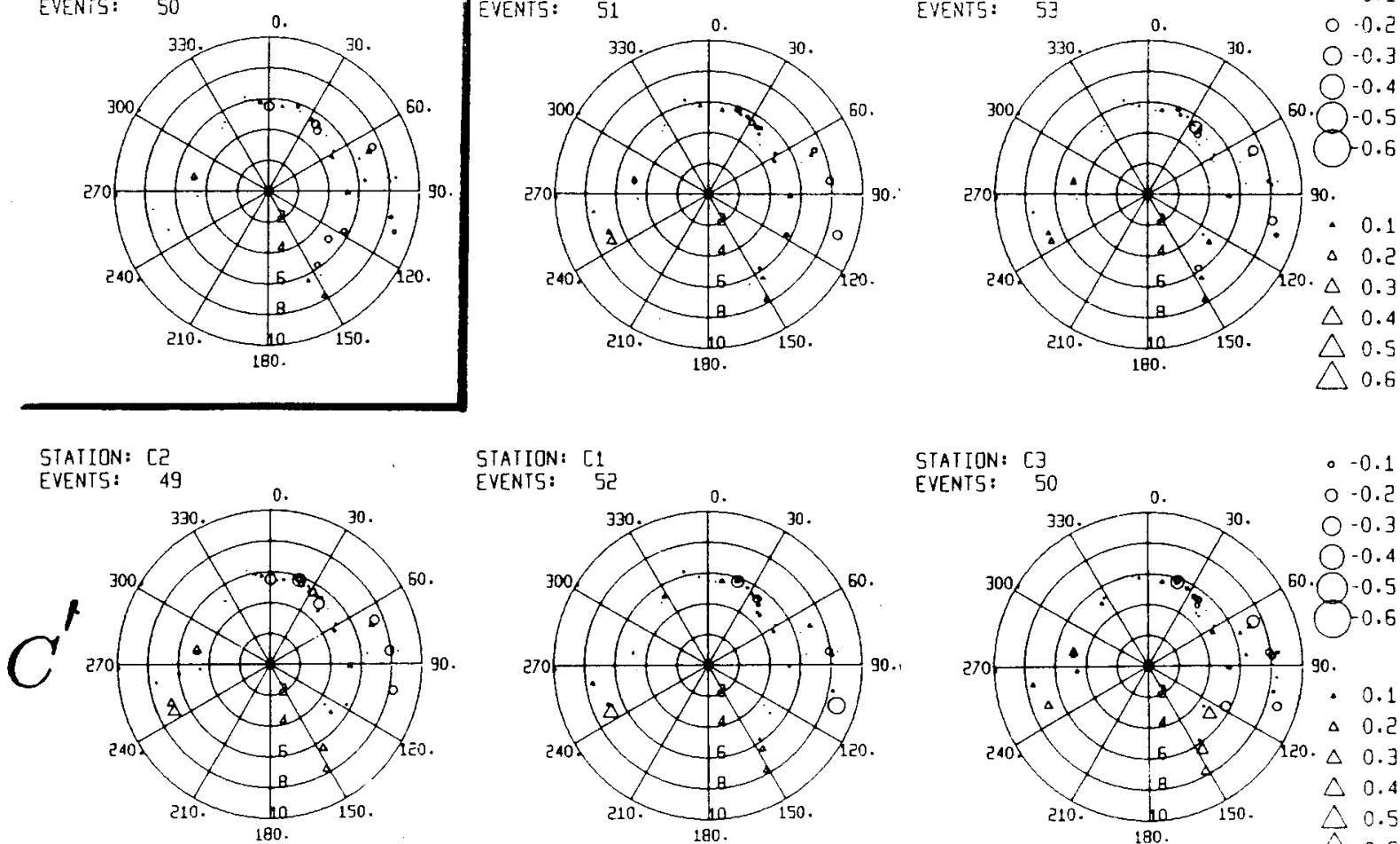

STAIION: $\quad[1$
EVENTS: 52
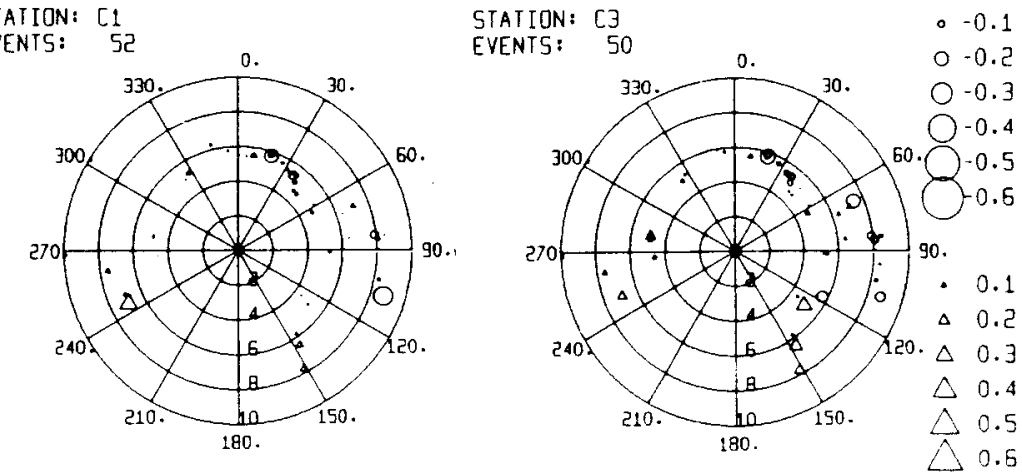

Figure 10. (Conitinued.) 


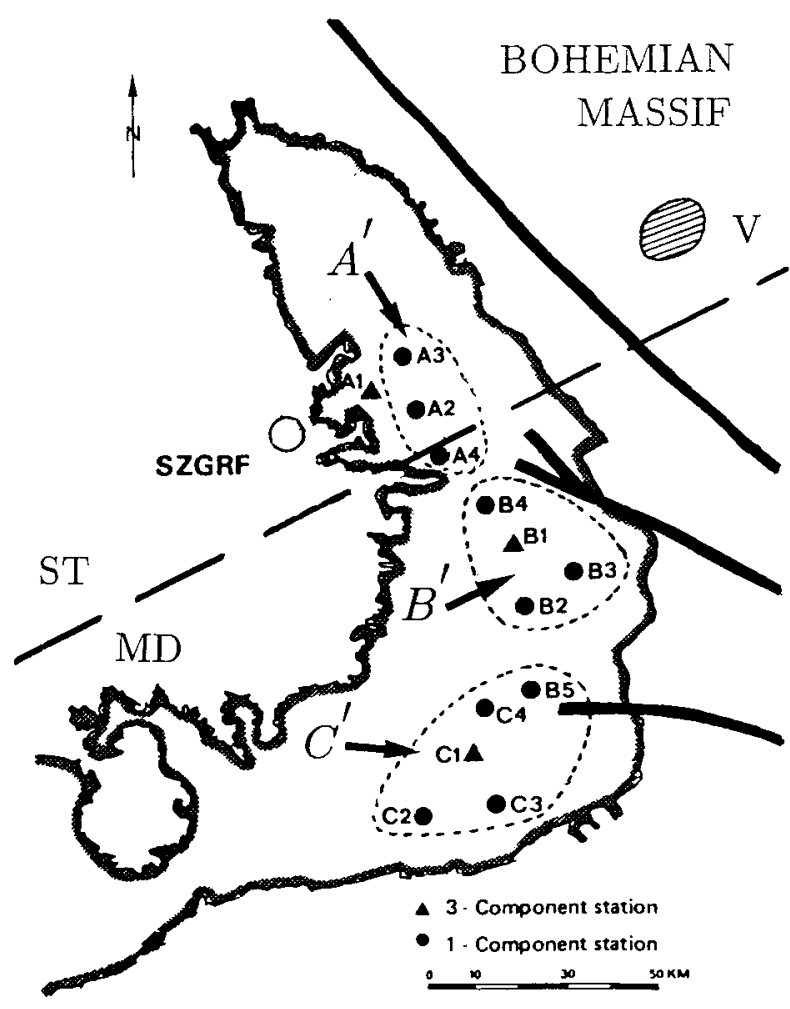

Figure 11. Clusters of GRF stations with similar $\Delta M_{X}^{i-a v}, \Delta T_{X}^{i-a v}$ patterns (Fig. 10), i.e. after the removal of the site effects $\Delta M_{X}^{\text {av }}$ and $\Delta T_{X}^{\text {av }}$ (Fig. 6). The solid lines indicate the main fault systems. The dashed line gives the border between the Saxothuringian zone (ST) and the Moldanubian zone (MD). The shaded area is the location of Cenozoic volcanism (V).

$A^{\prime}$ in Fig. 10(a) are rather small. They vary only between -0.2 and $+0.2 \mathrm{~s}$. The corresponding amplitude pattern in Fig. 10(b) is more pronounced. Small amplitudes (circles) are observed for events in the north-east and less consistently in the south-east together with larger amplitudes (triangles) for western back azimuths. $\Delta M_{X}^{i-\text { av }}$ reaches values of -0.29 to +0.29 magnitude units.

The magnitude pattern becomes more pronounced in cluster $B^{\prime}$ where the residuals are between -0.37 and +0.40 magnitude units. The regions of small amplitude anomalies (circles) are again in the north-east and south-east. The positive magnitude residuals stretch from west to east and a patch of triangles can also be observed at a slowness of about $8 \mathrm{~s} \mathrm{deg}^{-1}$ and a back azimuth of about $20^{\circ}$. The traveltime residuals of cluster $B^{\prime}$ show a pattern almost identical to that of the amplitude residuals with values between -0.7 to $+0.4 \mathrm{~s}$.

The main change from cluster $B^{\prime}$ to cluster $C^{\prime}$ is a further increase in the strength of the anomalies. The azimuthaland distance-dependent residuals in cluster $\mathrm{C}^{\prime}$ reach values of up to -0.8 to $+1.1 \mathrm{~s}$ in traveltime and -0.54 to +0.72 in magnitude units. The pattern of traveltime residuals resembles that of cluster $B^{\prime}$ with the exception of the eastern back azimuth which in cluster $\mathrm{C}^{\prime}$ is fast and small. The slow anomaly (triangles) between the back azimuth of $120-150^{\circ}$ becomes one of the dominating features in the traveltime residual pattern of Fig. 10(a). The pattern of magnitude residuals in cluster $C^{\prime}$ in Fig. 10(b) again correlates well with the corresponding traveltime residual pattern in Fig. 10(a).

The other frequency bands give almost identical results, i.e. same clusters of stations with similar patterns and values for the traveltime and magnitude residuals. The sole exceptions are the magnitude residuals of the WWSSN-LP filter (Fig. 10c), which still show about the same clusters and pattern, but the size of the magnitude residuals is drastically reduced to half or less of the residuals in the WWSSN-SP filter.

In the following, possible reasons for the features of anomalous traveltime and amplitude residuals shown in Fig. 10 are discussed. A pattern of relative traveltime or amplitude anomalies observed at all 12 stations in Fig. 10 is most likely produced by an anomaly close to the reference station A1, whereas features occurring only at subsets of the stations are due to inhomogeneities near these stations.

The small amplitudes and fast traveltimes (circles) visible in the north and north-east in Fig. 10 are most likely produced by a low-velocity anomaly in the lithosphere north to north-east of the array. Such an anomaly has been postulated by Faber et al. (1986, Fig. 11; depth larger than $150 \mathrm{~km}$, distance from Al about $75 \mathrm{~km}$ ) and by Nixdorf (1986, Fig. 40, depth between 50 and $100 \mathrm{~km}$, distance from A1 about $20 \mathrm{~km}$ ). The tectonic feature related to such an anomaly could be the boundary between the Saxothuringian zone (ST) in the north and the Moldanubian zone (MD) in the south, which crosses the array approximately in an east-north-easterly direction (Fig. 11). The low-velocity body could be connected to the Cenozoic volcanism (shaded area in Fig. 11) and a graben structure further north-east of the array (Faber et al. 1986; Nixdorf 1986).

The patch of triangles (slow traveltime residuals and large-amplitude residuals) at a slowness of about $8 \mathrm{~s} \mathrm{deg}^{-1}$ and a back azimuth of about $20^{\circ}$ is most likely due to a shallow (crustal) high-velocity anomaly north-north-east of station A1, since all stations south of the reference station $\mathrm{A} 1$ and of station $\mathrm{A} 3$ show these positive relative residuals.

The second significant pattern of fast traveltime and small-amplitude anomalies (circles) moves from about $120^{\circ}$ to $180^{\circ}$ back azimuth in cluster $B^{\prime}$ to about $90^{\circ}$ to $120^{\circ}$ in cluster $C^{\prime}$. Such behaviour with respect to the reference station A1 has already been noted by Faber et al. (1986) and indicates a high-velocity anomaly south-east of cluster $B^{\prime}$ and east-south-east of cluster $C^{\prime}$ in the subcrustal layers under the Moldanubian part of the Bohemian Massif. The mislocation vectors in Faber et al. (1986) and Krüger \& Weber (1992) also indicate an increase in velocity for these back azimuths.

One of the most pronounced anomalies with triangles (slow and large) appears for the southernmost stations, i.e. cluster $C^{\prime}$, between back azimuths of about $120-150^{\circ}$. This back azimuth range was not well covered by Faber $e t$ al. (1986) but is now well sampled. The corresponding low-velocity anomaly is most likely located in crust or upper lithosphere towards the south-east of cluster $C^{\prime}$, since it is not observed in cluster $B^{\prime}$. Tectonic features connected with such a low-velocity structure could be the offset of the Donau-Randbruch (open triangle in Fig. 7b) and/or the rapid increase of the Moho depth in a south-south-easterly 
direction (see, e.g. Giese 1990; Hadiouche, Krüger \& Kind 1991).

The large and slow relative residuals (triangles), visible at all stations for western back azimuths, are most likely due to high-velocity anomaly west of station A1, possibly connected to the western edge of the Franconian Jura. The large and slow relative residuals for eastern back azimuths only visible in cluster $B^{\prime}$ could be produced by a shallow low-velocity anomaly east of cluster $\mathrm{B}^{\prime}$. Such a low-velocity body has been located in this area from refraction surveys at a depth of between 35 and $45 \mathrm{~km}$ by Strößenreuther (1982).

The modelling of the amplitude and traveltime residuals for these structures would require the computation of the complete wavefield using 3-D finite-difference (FD) methods. Other methods that do not model the full waveform effects from complicated 3-D structures will severely underestimate the structural complexities. An example for the rapid variation from large positive to large negative traveltime and magnitude residuals over a narrow back azimuth range can, for example, be observed at about $120^{\circ}$ for station C3 in Figs 10(a) and (b). Only FD methods will be able to describe correctly the frequency-dependent focusing-defocusing effects and the influence of the size and strength of the inhomogeneities (scatterers). An indication of such a frequency-dependent effect can be seen by comparing the WWSSN-SP and WWSSN-LP magnitude residuals (Fig. 10b versus c). Sinilar effects have also been reported by Odegaard \& Doornbos (1993) and are not too surprising since the wavelength of the $P$ waves in WWSSN-SP is about six times smaller than in WWSSN-LP. Another wavefield feature that cannot be modelled by high-frequency approximations are diffractions from sharp discontinuities and/or offsets like the boundary between the eastern part of the South German block (Franconian Jura) and the Bohemian Massif (Fig. 11). Presently such a 3-D modelling attempt, especially in an inversion procedure, is not feasible.

The conclusion from this section is that several inhomogeneities are responsible for the amplitude and traveltime pattern observed at the GRF array. The amplitude and traveltime residuals due to high- and lowvelocity anomalies in the crust and lithosphere below, and in the vicinity of, the array are partially masked by effects from near-surface sediment. The reliable separation of focusing-defocusing effects due to dipping and curved interfaces, scattering at inhomogeneities of different scale length and strength and of diffractions from sharp offsets at faults will only become possible if full waveform modelling in three dimensions becomes feasible. Another prerequisite will, furthermore, be a better coverage with seismic stations in the vicinity of the array. Nevertheless, it is already possible to locate the anomalies most likely responsible for the strongly distance- and back-azimuth-dependent traveltime and magnitude residuals observed at the array.

\section{DISCUSSION AND CONCLUSION}

The analysis of teleseismic $P$-wave traveltime and amplitude variations across the German seismic broad-band array GRF in four frequency bands reveals that traveltime and amplitude anomalies (residuals) are closely related. Small (large) ampiitudes consistently occur for fast (slow) traveltimes. LP amplitude residuals are much smaller than the SP amplitude residuals. The strong azimuthal and distance dependence of the relative residuals with respect to the reference station $A 1$ indicates, together with the frequency dependence of the amplitude residuals, that complex 3-D structures exist under and in the vicinity of the array.

The influence of the varying thickness of the surficial sediment layers on the relative traveltime and amplitude residuals was modelled with the reflectivity method. These shallow layers account for about $40-60$ per cent of the station averages (site effects) of the traveltime residuals in al frequency ranges except for WWSSN-LP. For short-period frequency bands amost 100 per cent of the magnitude residuals are due to these thin layers in the topmost kilometre. These azimuthal-independent terms (site effects) of up to $-0.55 \mathrm{~s}$ and -0.15 magnitude units show a clear regional clustering and grouping connected to the local geology. Although it is difficult to separate the near-surface site effect from the effects of crustal and uppermost mantle structure there is evidence, that a continuous increase in crustal and uppermost mantle velocity from north to south across the array (see, e.g. Faber et al. 1986, Figs 9 and 10; Nixdorf 1986) could explain most of the remaining part of the station average of the traveltime residuals.

If the site effect is subtracted, the azimuthal- and distance-dependent relative residuals with respect to $A 1$ (i.e. $\Delta T_{X}^{i-a v}$ and $\Delta M_{X}^{i-a v}$ in Fig. 10) also show consistent patterns in traveltime and magnitude. These anomalies vary up to $1.9 \mathrm{~s}$ and 1.2 magnitude units at single stations (sec, e.g. stations $\mathrm{C} 2$ and $\mathrm{C} 3$ in Figs $10 \mathrm{a}$ and b, respectively) These large variations and the patterns are produced by several high- and low-velocity inhomogeneities in the crust and upper mantle in the vicinity of the array. Most of theso anomalies correlate with local surface geology, regional geological structures in the area of the array, some of which are still seismically active, and the larger geological units in south-eastern Germany. One of the most prominent features is a low-velocity anomaly in the upper mantle to the north-east of the array, possibly connected to the transition region between the Saxothuringian zone and the Moldanubian zone (Nixdorf 1986). This inhomogeneity and the high velocities towards the east-south-east in the uppermost mantle under the Moldanubian part of the Bohemian Massif have previously been derived aiso by Faber et al. (1986) from traveltimes. Two low-velocity features responsible for slow traveltime and large-amplitude residuals are situated east of subarray $B$ and south-east of subarray $C$, respectively. The first of these anomalies could be the low-velocity lense derived from refraction data by Strößenreuther (1982) and the second could be due to the main faults south-east of the array and/or to the dip of the Moho towards the Alps.

Further work will be necessary to determine the extent and the structure of these inhomogeneities and their influence on the wavefield recorded at the individual stations of the array. This becomes especially clear if the rapid variation of the traveltime and magnitude residuals in the back azimuth range of $115-130^{\circ}$ at the southern stations is considered. In this narrow back azimuth window the relative traveltime residuals change from -0.8 to $+1.1 \mathrm{~s}$ and the magnitude residuals vary from -0.4 to +0.6 magnitude 
units. Standard high-frequency approximations usually employed in the modelling of 3-D structure will not be able to describe reliably the observed complicated wavefield, which could be due to diffractions from offsets and discontinuities at the main faults, scattering at inhomogeneities of different size and strength, together with focusing and defocusing from curved interfaces and smoothly varying velocity gradients.

The strong variation of traveltime as a function of back azimuth and source-receiver distance between the closely spaced stations of the array points also to one of the problems in delay-time tomography on regional and global scales. Simple azimuthal-dependent station corrections (see, e.g. Dziewonski \& Anderson 1983) will smooth out this complicated and rapidly varying function. The deviations from this smooth function will then be mapped into deeper structure, or at least decrease the data quality severely by increasing the scatter of the data. The only way to avoid such an unwanted bias is the detailed study and consideration of the near-receiver effects before tomographic inversions are applied.

\section{ACKNOWLEDGMENTS}

I thank K. Stammler for his program to analyse and process the data. I would also like to thank F. Krüger, G. Müller, J. Plomerová, J. Schlittenhardt and an anonymous reviewer for their comments on this paper, and the Deutsche Forschungsgemeinschaft (DFG) for financing this research. The Gräfenberg-array is operated by the Bundesanstalt für Geowissenschaften und Rohstoffe (BGR) and funded by the DFG.

\section{REFERENCES}

Aichele, H., 1976. Interpretation Refraktionsseismischer Messungen im Gebiet des Fränkisch-Schwäbischen Jura, $P h D$ thesis, Universität Stuttgart.

Aki, K., 1973. Scattering of $P$ waves under the Montana LASA, $J$. geophys. Res., 78, 1334-1347.

Aki, K., 1993. Local site effects on weak and strong ground motion, Tectonophysics, 218, 93-111.

Aki, K., Christoffersson, A. \& Husebye, E.S., 1977. Determination of the three-dimensional structure of the lithosphere, $J$. geophys. Res., 82, 277-296.

Bader, K., 1982a. Die seismischen Geschwindigkeiten bis zum Grundgebirge bei der Forschungsbohrung Dinkelsbühl 1001, Geol.Bav., 83, 87-88.

Bader, K., 1982b. Die Grundgebirgstife längs eines Profils von Burgthann bis Beilingries aufgrund Refraktionsseismischer Messungen, Geol. Bav., 83, 123-127.

Berteussen, K.-A., Christoffersson, A., Husebye, E.S. \& Dahle, A., 1975. Wave scattering in analysis of $P$-wave anomalies observed at NORSAR and LASA, Geophys. J. R. astr. Soc., 42, 403-417.

Breyer, F., 1956. Eïgebnisse seismischer Messungen auf der Süddeutschen Großscholle besonders im Hinblick auf die Oberfläche des Varistikums, Z. Deutsch. geol. Ges., 108, 21-36.

Breyer, F., 1972. Versuche zur geologischen Erkundung des Untergrundes in Mittel- und Ostfranken mittels gravimetrischer und seismischer Messungen, Z. Deutsch. geol. Ges., 123, 233-258.

Butler, R., 1983. $P$-wave travel time and amplitude in western
North America, Nature, 306, 677-678.

Chang, A.C. \& von Seggern, D.H., 1980. A study of amplitude anomalies and $m_{b}$ bias at LASA subarrays, J. geophys. Res., $85,4811-4828$.

Cranswick, E., 1988. The information content of high-frequency seismograms and the near-surface geologic structure of 'hard rock' recording sites, Pageoph, 128, 333-363.

Cranswick, E., King, K., Carver, D., Worley, D., Williams, R., Spudich, P. \& Banfill, R., 1990. Site response across downtown Santa Cruz, California, Geophys. Res. Lett., 17, 1793-1796.

Dziewonski, A. \& Anderson, D.L., 1983. Traveltimes and station corrections for $P$ waves at teleseismic distances, J. geophys. Res., 88, 3295-3314.

Faber, S., Plomerová, J. \& Babuška, V., 1986. Deep seated lateral velocity variations beneath the GRF-array inferred from mislocation patterns and $P$ residuals, $J$. Geophys., 60, 139-148.

Flatté, S.M. \& Wu, R.S., 1988. Small-scale structure in the lithosphere and asthenosphere deduced from arrival time and amplitude fluctuations at NORSAR, J. geophys. Res., 93, 6601-6614.

Fuchs, K. \& Müller, G., 1971. Computation of synthetic seismograms with the reflectivity method and comparison with observations, Geophys. J. R. astr. Soc., 23, 417-433.

Geologische Karte von Bayern 1:500,000 (3. Auflage), 1981. Bayr. Geolog. Landesamt, München.

Giese, P., 1976. Results of the generalized interpretation of the decp-seismic sounding data, in Explosion Seismology in Central Europe, Data and Results, pp. 201-214, eds Giese, P., Prodehl, C. \& Stein, A., Springer, Berlin.

Giese, P., 1990. Crustal thickness in Central Europe, in Proceedings of the Fifth Workshop on the European Geotraverse (EGT)-Integrative studies, pp. 115-119, eds Freeman, R., Giese, P. \& Müller, St., European Science Foundation, Strasbourg.

Greiner, G. \& Lohr, J., 1980. Tectonic stresses in the northern foreland of the Alpine system measurements and interpretation, Rock Mech., Suppl. 9, 5-15.

Gudden, H., 1970. Stratigraphische Gliederung einiger Tiefbohrprofile in die höhere Trias unter der nördlichen Frankenalb anhand bohrlochphysikalischer Messungen (Tiefbohrungen Eschenfelden B1 und B2), Geol. Bl. NO-Bayern, 20, 105-119.

Gudden, H., 1981. Über Thermal-Mineralwasserbohrungen im Coburger Umland, J. Ber. Mitt. Oberrhein. Geol. Verh., 63, 229-252.

Gudden, H., 1982. Die Forschungsbohrung Berching 1977, Konzeption, Ablauf und Deutung der Ergebnisse, Geol. Bav., 83, 95-112.

Gudden, H., 1989. Abenberg 1001, in Geowissenschaftliche Gemeinschaftsaufgaben, Tätigkeitsbericht 1987/1988, pp. 6772, Niedersächsisches Landesamt für Bodenforschung, Hannover.

Gudden, H. \& Schmid, H., 1985. Die Forschungsbohrung Obernsees-Konzeption, Durchführung und Untersuchung der Metallführung, Geol. Bav., 88, 5-21.

Haddon, R.A.W. \& Husebye, E.S., 1978. Joint interpretation of $P$-wave time and amplitude anomalies in terms of lithospheric heterogeneities, Geophys. J. R. astr. Soc., 55, 19-43.

Hadiouche, O., Krüger, F. \& Kind, R., 1991. Mapping the crust in southeastern Germany using Rayleigh waves in the period range 6-16s, Geophys. Res. Lett., 18, 1087-1090.

Harjes, H.P. \& Hanka, W., 1986. The contribution of broadband array seismology to seismic monitoring of underground nuclear explosions, in Ten years of the Gräfenberg Array, pp. 105-120, ed. Buttkus, B., Geol. Jahrb., $\mathbf{E 3 5}$.

Jiménez, J.J., 1993. Calibracion de una red sismica para la localizacion de terremotos lejanos. Aplicacion a la red sismica suiza, PhD thesis, Universidad Complutense de Madrid. 
Kennett, B.L.N. \& Engdahi, E.R., 1991. Traveltimes for global earthquake location and phase identification, Geophys. J. Int., 105, 429-465.

Krüger, F., 1994. Sediment structure at GRF from polarisation analysis of $P$-waves of nuclear explosions, Bull. seism. Soc. Am., 84, 149-170.

Krüger, F. \& Weber, M., 1992. The effect of low-velocity sediments on the mislocation vectors of the GRF array, Geophys. J. Int., 108, 387-393.

Leydecker, G., 1986. Erdbebenkatalog für die Bundesrepublik Deutschland mit Randgebieten für die Jahre 1000-1981, Geol. Jahrb., E36.

Liu, Q. \& Kind, R., 1986. Lateral variation of the structure of the crust-mantle boundary from conversions of teleseismic $P$-waves, $J$. Geophys., 60, 149-156.

Mori, J. \& Frankel, A., 1992. Correlation of $P$ wave amplitude and travel time residuals for telescisins recorded on the southern California seismic network, J. geophys. Res., 97, 6661-6674.

Müller, G., 1985. The reflectivity method: a tutorial, J. Geophys., 58, 153-174.

Nakanishi, I. \& Motoya, Y., 1990. Teleseismic $P$-wave travel time and amplitude anomalies observed in Hokkaido region, Japan, J. Phys. Earth, 38, 163-177.

Nixdorf, U., 1986. Teleseismische Laufzeitresiduen in Bayern von 1979 bis 1984 und ihre Auswertung mittels strahlenseismischer Modellrechnungen, Diploma thesis, L.M. Universität München.

Odegaard, E. \& Doornbos, D.J., 1993. Seismic tomography of array data, J. geophys. Res., 98, 4377-4388.

Plomerová, J. \& Babuška, V., 1988. Lithospheric thickness in the contact zone of the Moldanubicum and Saxothuriigicum in central Europe, Phys. Earth planet. Inter., 51, 159-165.

Salgør, M. \& Schmid, H., 1982. Die Forschungsbohrung
Eschertshofen 1981 (Vortäufige Mitteilung), Geol. Etu, 83, $145-161$

Schmid, H., 1982. Die Forschungsbohrung Kalimünz, (Kurzmit teilung), Geol. Bav., 83, 163-165.

Schmidt-Kaler, H., 1969. Keuper und Jura in der Tiefbohrung Riedenburg, Geol. Bl. NO-Bayern, 19, 97-112.

Schmidt-Kaler, H., 1985. Das geologische Profil der Thermalwasserbohrung Bad Abbach südlich Regensburg (Grundgebirge bis Kreide): Stratigraphische Gliederung und Paläogeographische Folgerungen, Geol. Bl. NO-Bayern, 34/35, 273-302.

Stammler, K., 1993. SeismicHandler-programmable multichannel data handler for interactive and automatic processing of seismological analyses, Comput. Geosci., 19, 135-140.

Stein, A., 1985. Refraktionsseismik und Geoelektrik in Mittelfranken, in Geowissenschaftliche Gemeinschaftsaufgaben, Tätigkeitsbericht 1983/1984, pp. 8-10, Niedersächsisches Landesamt für Bodenforschung, Hannover.

Stein, A., 1989. Refraktionsseismik in Mittelfranken, in Geowissenschaftliche Gemeinschafisaufgaben, Tätigkeitsberich 1987/1988, pp. 21-22, Niedersächsisches Landesamt für Bodenforschung, Hannover.

Strößenreuther, U., 1982. Die Struktur der Erdkruste am Südwest-Rand der Böhmischen Masse, abgeleitet aus refraktionsseismischen Messungen der Jahre 1970 und 1978/1979, PhD thesis, L.M. Universität München.

Thomson, C.J., 1983. Ray-theoretical amplitude inversion for latcraily varying velocity structure below NORSAR, Geophys. J. R. astr. Soc, , 74, 525-558.

Thomson, C.J. \& Gubbins, D., 1982. Three-dimensional lithos pheric modelling at NORSAR: linearity of the method and amplitude variations from the anomalies, Geopinys. J. K. anir. Soc., 71, 1-36. 